\title{
Sexualized Labour in Digital Culture: Instagram Influencers, Porn Chic and the Monetization of Attention
}

Jenna M. Drenten

Loyola University Chicago, jdrenten@luc.edu

Lauren Gurrieri

Meagan Tyler

Follow this and additional works at: https://ecommons.luc.edu/business_facpubs

Part of the Business Commons, Gender, Race, Sexuality, and Ethnicity in Communication Commons, and the Social Media Commons

Author Manuscript

This is a pre-publication author manuscript of the final, published article.

\section{Recommended Citation}

Drenten, Jenna M.; Gurrieri, Lauren; and Tyler, Meagan. Sexualized Labour in Digital Culture: Instagram Influencers, Porn Chic and the Monetization of Attention. Gender, Work and Organization, Early View: Online, : , 2019. Retrieved from Loyola eCommons, School of Business: Faculty Publications and Other Works, http://dx.doi.org/10.1111/gwao.12354

This Article is brought to you for free and open access by the Faculty Publications and Other Works by Department at Loyola eCommons. It has been accepted for inclusion in School of Business: Faculty Publications and Other Works by an authorized administrator of Loyola eCommons. For more information, please contact ecommons@luc.edu.

\section{(c) (1) $\odot \Theta$}

This work is licensed under a Creative Commons Attribution-Noncommercial-No Derivative Works 3.0 License. (c) John Wiley \& Sons Ltd 2019 
Drenten, Jenna, Lauren Gurrieri, and Meagan Tyler (2019), "Sexualized Labour in the Digital Era: Instagram Influencers, Porn Chic and the Monetization of Attention," Gender, Work and Organization, 1-26. DOI:10.1111/gwao.12354

Note: This is a preprint version. The final published version of the paper may reflect notable format and content changes.

\title{
SEXUALISED LABOUR IN DIGITAL CULTURE: INSTAGRAM INFLUENCERS, PORN CHIC AND THE MONETISATION OF ATTENTION
}

\begin{abstract}
The rise of digital technologies and social media platforms has been linked to changing forms of work, as well as the mainstreaming of pornography and a 'porn chic' aesthetic. This article examines some of the ways in which these themes coalesce, and interrogates the conceptual boundaries of sexualised labour, extending beyond traditional organisational settings, and into Web 2.0. The study explores performances of sexualised labour on social media by analysing visual and textual content from 172 female influencers on Instagram. Our paper contributes to the literature on sexualised labour in three ways. First, by demonstrating how sexualised labour is enacted across various forms of influencer labour, and how this relates to the attention economy and monetisation. Second, by developing the extant conceptualisation of sexualised labour and introducing connective labour as a required element to mobilise sexualised labour. Third, by opening up a critical analysis of what is meant by 'sexualised' labour within a cultural context of pornographication.
\end{abstract}

Keywords: Sexualised Labour; Influencers; Instagram; Prosumption; Sexualisation 


\section{SEXUALISED LABOUR IN DIGITAL CULTURE: INSTAGRAM INFLUENCERS, PORN CHIC AND THE MONETISATION OF ATTENTION}

Research increasingly attends to the role of the prosumer in explorations of work, consumption and organisations (Dujarier, 2016; Gabriel, Korczynski, \& Rieder, 2015; Zwick, Bonsu, \& Darmody, 2008). The prosumer bridges the traditional divide between consumption and production (Cova \& Dalli, 2009; Ritzer \& Jurgenson, 2010), carrying out a variety of productive activities in their role as consumers. Scholars highlight the role of digital technologies in facilitating the rise of consumers as workers and expanding prosumption practices (Büscher \& Igoe, 2013; Ritzer, Dean, \& Jurgenson, 2012). One key area in which this can be illustrated is the explosion of user-generated content online, whereby consumers of Web 2.0 platforms are actively involved in the production process of content that is co-opted for the social, cultural and economic value it generates (Bonsu \& Darmody, 2008; Fuchs, 2013). For some, this highlights the ways in which prosumption serves to perpetuate existing power relationships within capitalism, particularly in relation to the exploitation and alienation of prosumers and the unpaid work they perform (Comor, 2011; Fontenelle, 2015). We are interested here in how prosumers and social media platforms, such as Instagram, relate to extant understandings of sexualised labour.

The ability to monetise the prosumer labour invested in generating this digital content hinges upon the amount of attention produced (Jin \& Feenberg, 2015). Within this 'attention economy', attention is both a scarce and valuable resource (Davenport \& Beck, 2001; Goldhaber, 1997) that functions as a form of capital, which, once measured, can be marketised and financed (Terranova, 2012). One consequence of this has been the explosion of 'influencer commerce' - with prosumers working to generate digital content and gain the attention of a 'following' on social media through representations of their everyday lives in which commodities play a vital role. Influencers are a type of 'microcelebrity' - a style of online performance in which individuals attempt to gain attention and popularity by employing digital media technologies, such as webcams, blogs, and social media (Senft, 2008). Influencer marketing on social media is now a multi-billion dollar industry, expected to be valued between $\$ 5$ to 10 billion by 2020 (MediaKix, 2018). The influencer category is dominated by women (Abidin, 2016a), who set the 'cultural scripts' adopted by everyday social media users - commonly on the platform Instagram. In turn, this leads to the generation of vast quantities of digital content that integrates promotions of products and services, work that is often utilised by brands without remuneration or with little compensation (Abidin, 2016b).

For influencers, the body plays a critical role in the 'selfies' that are the end product of their prosumer labour. For the women who upload these self- 
representations to social media, conformance to heteronormative prescriptions of attractiveness and femininity is fundamental in gaining attention (Duffy, 2017). This is enacted through a range of fashion and beauty practices, appropriate lighting and posturing and the use of image-enhancing and photo-editing applications that in turn maximise the number of 'likes' on a post - a quantification of attention and monetisation potential (Abidin, 2016a). It has been observed that women's selfpresentation on social media is highly sexualised (Carrotte, Prichard, \& Lim, 2017; Hall, West, \& Mclntyre, 2012; Kapidzic \& Herring, 2015; Manago, Graham, Greenfield, \& Salimkhan, 2008; Ringrose, 2011). Posting sexualised photos on social media has been related to wider cultural pressures that convey to women sexiness is both valued and a means of gaining attention (Daniels, 2016). Today, what has increasingly come to constitute sexiness in online environments is 'porn chic' - a style that reflects the mainstreaming of the aesthetics of commercial pornography within Western societies (Lynch, 2012; Tyler \& Quek, 2016). There is no single way that porn chic manifests in popular culture, although a core element can be understood as making women appear 'fuckable' (Dines, 2015) to a (generally assumed male) audience. This fragmenting and blurring of pornographic imagery into traditionally non-pornographic forms of popular culture-also known as pornographication-has been heavily facilitated by the rise of the internet and associated digital technologies (Attwood, 2011; Boyle, 2010, 2018; Dines, 2010; McNair, 2002, 2013; Paasonen, Nikunen, \& Saarenmaa, 2007; Paul, 2005).

In this paper, we aim to develop new directions for the analysis of sexualised labour by extending its performance beyond the traditional dyadic perspective of management-worker. We examine how sexualised labour is performed by influencers in the digital era and its precarious potential to be monetised by generating attention, which for women is structured by cultural expectations of 'porn chic' sexiness. In doing so, we consider how prosumption as enacted in digital culture subscribes to and challenges extant understandings of sexualised labour. Our paper contributes to understandings of sexualised labour in three ways. First, we develop the extant conceptualisation of sexualised labour by conceiving it as an embodied performance that involves a complex, inter-related dynamic of emotion, aesthetics and a modality of 'sexualisation' that cannot be separated from where it is placed. This is mobilised by what we term connective labour - the practices, skills and knowledge employed to successfully embody and negotiate this performance for attention and monetisation purposes. Second, we demonstrate how sexualised labour is enacted across five forms of influencer labour in digital culture (i.e., hopefuls, boasters, engagers, boosters, and performers), supporting self-commodification which unfolds on a continuum from nonmonetised and low attention practices (i.e., affiliation-based influencer labour) to monetised and high attention practices (i.e., access-based influencer labour). Third, we offer a critical analysis of what is meant by 'sexualised' labour beyond the recognised 
elements of sexuality, sexual desire, and/or sexual pleasure (Spiess \& Waring, 2005; Tyler, 2012; Warhurst \& Nickson, 2009). Specifically, we query that the concept of sexualised labour generally incorporates all labour that has a sexual or sexualised element, but this tells us little about the specificity of the practices and their underlying power dynamics. We argue for the consideration of possible modalities of sexualised labour that interrogate the relationship between 'sexualisation' and the shaping role of cultural norms and power dynamics in this process, in particular, the influence of 'porn chic'.

In exploring these ideas, our paper is structured as follows. First, we review literature on sexualised labour and consider its conceptualisation. Second, we present our research study, which examines performances of sexualised labour on the social media platform Instagram. We analyse visual and textual content from 172 female Instagram influencers, both aspiring and established, as sampled through curatorial sexualised 'shoutout pages' that function as attention currency. Third, we present our research findings that demonstrate how prosumers perform sexualised labour on Instagram through a meshing of aesthetic labour, emotional labour and a 'porn chic' sexualisation across five forms of influencer labour, which is mobilised by what we term connective labour. We conclude by discussing how our research contributes to extant conceptualisations of sexualised labour in relation to: the issue of freely chosen versus prescribed sexualised labour; the addition of connective labour as a key element of sexualised labour, and; questioning the meaning of 'sexualised'.

\section{Sexualised labour: emotional labour, aesthetic labour and sexualisation (?)}

Sexualised labour is understood as work that becomes associated with sexuality, sexual desire and sexual pleasure (Spiess \& Waring, 2005; Tyler, 2012; Warhurst \& Nickson, 2009). The concept grew out of the need to better understand the role of employee corporeality and the sexualisation of employees in undertaking forms of emotional and aesthetic labour. We draw on two key conceptualisations of sexualised labour from the available literature (Tyler, 2012; Warhurst \& Nickson, 2009). Warhurst and Nickson $(2009$, p. 385) argue a 'conceptual double shift' is needed to understand how employees become sexualised - firstly, as a linear shift from "emotional to aesthetic and sexualised labour and secondly, from an employee sexuality that is sanctioned and subscribed to by management to that which management strategically prescribes". Tyler (2012, p. 914), on the other hand, conceives sexualised labour as a process through which "work becomes associated, either implicitly or explicitly, with the provision and pursuit of sexual pleasure". This moreover encompasses a complex dynamic of emotion, aesthetics and sexuality, the performance of which cannot be separated from where it is placed. Common to both 
conceptualisations, is that emotion, aesthetics and sexualisation underpin the performance of sexualised labour. Each of these aspects will be considered next.

The first element of this conceptualisation is emotional labour, which constitutes "the management of feeling to create a publicly observable facial and bodily display [which] is sold for a wage and therefore has exchange value" (Hochschild, 1983, p. 7). It is a dramatic performance that necessitates the active management of emotions requiring an individual "to induce or suppress feeling in order to sustain the outward countenance that produces the proper state of mind in others (Hochschild, 1983, p. 7). According to Hochschild (1983), the performance of emotional labour is enacted through surface acting - a body-language performance of facial expressions, gestures and voice tone that conveys an appropriate image - and deep acting - which involves a method form of acting through which employees regulate their emotions to align with their work and its required displays. Understanding and evoking the appropriate emotional performance in a given situation is critical. These 'feeling rules' or 'display rules' may be explicitly stated (e.g. training manual, policies of customer conduct) or implicitly learned through organisational culture and norms (Ashforth \& Humphrey, 1993; Grandey, 2000; Hochschild, 1983). However, such an analysis may elide over employees seeking out particular occupations to express their identities (Korczynski, 2003; Schweingruber \& Berns, 2005). As such, there is a need to distinguish between emotional work that occurs in response to the requirements of one's job and emotional labour which occurs more routinely in managing our emotions (Bolton \& Boyd, 2003). The motives for workplace emotion (Bolton, 2005) may range from pecuniary (material and commercial gain), prescriptive (abiding by professional norms of conduct), presentational (abiding by social norms) and philanthropic (performed as a 'gift' to others). Regardless, all such emotional displays require effort (Morris \& Feldman, 1996) and foreground the centrality of the body.

The second aspect of sexualised labour is aesthetic labour, whereby workers' embodied capacities and attributes are incorporated into the labour process to evoke sensory affect in customers and commercial benefits for organisations (Dean, 2005; Entwistle \& Wissinger, 2006; Tyler, 2011; Witz, Warhurst, \& Nickson, 2003). Although related concepts exist, aesthetic labour is focused on work in which "individuals are compensated, indirectly or directly, for their own body's looks and affect" - as opposed to body work (unpaid work on one's own body) and bodily labour (paid work on others' bodies) (Mears, 2014, p. 1332). This emphasis on 'looking good and sounding right' (Warhurst \& Nickson, 2001) is moreover recognised as steeped in race, class and gender inequalities (Mears, 2014; Tyler \& Taylor, 1998). In turn, these aesthetics are mobilised, developed and commodified across a range of work contexts. Most research on aesthetic labour focuses on organisational settings, especially interactive services, and the ways in which workers' bodies are recruited and 
controlled to embody the aesthetics of the organisation and promote its products and services (Spiess \& Waring, 2005; Warhurst \& Nickson, 2007; Witz et al., 2003). This aesthetic may also be driven by consumer tastes in the market contexts in which organisations are situated (Otis, 2011). Research has also turned to freelance or 'nonstandard' labour contexts, such as fashion models (Entwistle \& Wissinger, 2006) and theatre and television performers (Dean, 2005), where aesthetic labour is not managerially prescribed. What is understood as aesthetically valuable is much more ambiguous and subject to change in freelance contexts. Freelancers often engage in the on-going production and maintenance of their embodied selves through work that both endures beyond the working day and requires the production of a 'personality'. In turn, this has highlighted some conceptual deficiencies of aesthetic labour as superficial work on the body's surface that ignores the physical and emotional effort required to keep up appearances (Entwistle \& Wissinger, 2006). Such a critique highlights the conceptual slippage that exists between aesthetic and emotional labour (Warhurst \& Nickson, 2007; Witz et al., 2003).

The final feature of sexualised labour relates to sexualisation, however, there is a lack of agreement in the literature as to how this is conceived. For some, sexual appeal - which is closely related to aesthetic labour and an organisationally prescribed 'look' - is fundamental in understanding how sexualised labour works to appeal to the senses of consumers. This differs from sexualised work that is employee driven - such as a 'sexualised look' that is displayed through comportment, dress and language and sanctioned or subscribed to by management (Warhurst \& Nickson, 2009). Spiess and Waring (2005) similarly focus upon the notion of a 'sexualised appeal' but locate the shift from aesthetic to sexualised labour as defined by the role of the customer in interpreting the organisation's aesthetic as sexualised, specified as "appealing to the sexual desires [our emphasis] of customers" (Spiess \& Waring, 2005, p. 198). This has signalled the "blurry distinction between aesthetic and sexualised labour" (Mears, 2014 , p. 1339) that exists. This blurriness is most clearly demonstrated in the case of those engaged in 'display work', a type of aesthetic labour that involves a high degree of sexualised bodily display as the point of the job (Mears \& Connell, 2016). For Tyler (2012), it is not simply an employee's 'look' that is sexualised, but rather their embodied sexual subjectivities which necessitates consideration of the social materiality in which such labour is enacted and made meaningful. In turn, sexualised labour "encompasses a much broader process through which work becomes associated, either implicitly or explicitly, with the provision and pursuit of sexual pleasure [our emphasis]" (Tyler, 2012, p. 914). Another stream of literature that has been associated with the concept of sexualised labour focuses on the commodification of sexuality, mostly in sales-service work (Adkins, 1995; Filby, 1992; Pringle, 1989). 
Indeed, sexuality is referenced in relation to sexualised labour by all key voices on this topic.

Yet, 'sexualised' has quite different connotations to sexuality. Namely, when a person (and by extension, their labour) is sexualised, they have been subjected to sexualisation, which is understood as "a problem of sexual objectification along with recognition of a culture that is more likely to reduce girls (and women) to sexual objects" (Tyler \& Quek, 2016, p. 10). An American Psychological Association (APA) report on the sexualisation of girls establishes sexualisation as synonymous with sexual objectification and explicitly separates sexualisation from sexuality (Zurbriggen et al., 2007). As Davis (2001) states, sexuality is healthy and positive whilst sexualisation is objectifying and degrading. Hence, important tensions exist in how 'sexualised' is to be understood when discussing sexualised labour. Considering this, the aim of this paper is two-fold. First, to explore what sexualised constitutes via an examination of influencer labour in digital culture, which for women is monetised by getting attention through communicating one's 'sexiness'. Second, to examine how prosumption as enacted in digital culture subscribes to and challenges extant understandings of sexualised labour. Given the aforementioned conceptual blurriness between aesthetic labour, emotional labour and sexualised labour, following Tyler (2012) and Entwistle and Wissinger (2006), we commence with a working conceptualisation of sexualised labour as an embodied performance that involves a complex, inter-related dynamic of emotion, aesthetics and sexualisation that cannot be separated from where it is placed.

\section{Research Context and Methodology}

To examine sexualised labour in a prosumer and digital context, we turn to Instagram, an image-based online social networking site with over 800 million users worldwide (Statista, 2018). Instagram, launched in 2010, is rooted in prosumption by harnessing the user-generated web. The platform is unique due to its focus on visual content-all uploaded content must include an image or videos, accompanied by optional captions, geolocation, and hashtags (e.g., searchable keyword hyperlinks). Digital editing tools are in-built, allowing users to adjust visual elements of their images and videos, including brightness, contrast, and colors. Shared content appears in a news feed and on the original user's profile. Users can interact through commenting, liking, tagging, mentioning, and private messaging. Instagram accounts can be public or private. Following other users on Instagram is not necessarily a reciprocal process. Figure 1 provides an illustrative anatomy of a typical Instagram post and user interface. This study employs a dual qualitative approach of visual and 
textual analysis of Instagram posts by influencers who engage in sexualised labour on the platform.

Figure 1. Basic Anatomy of an Instagram Post and User Interface

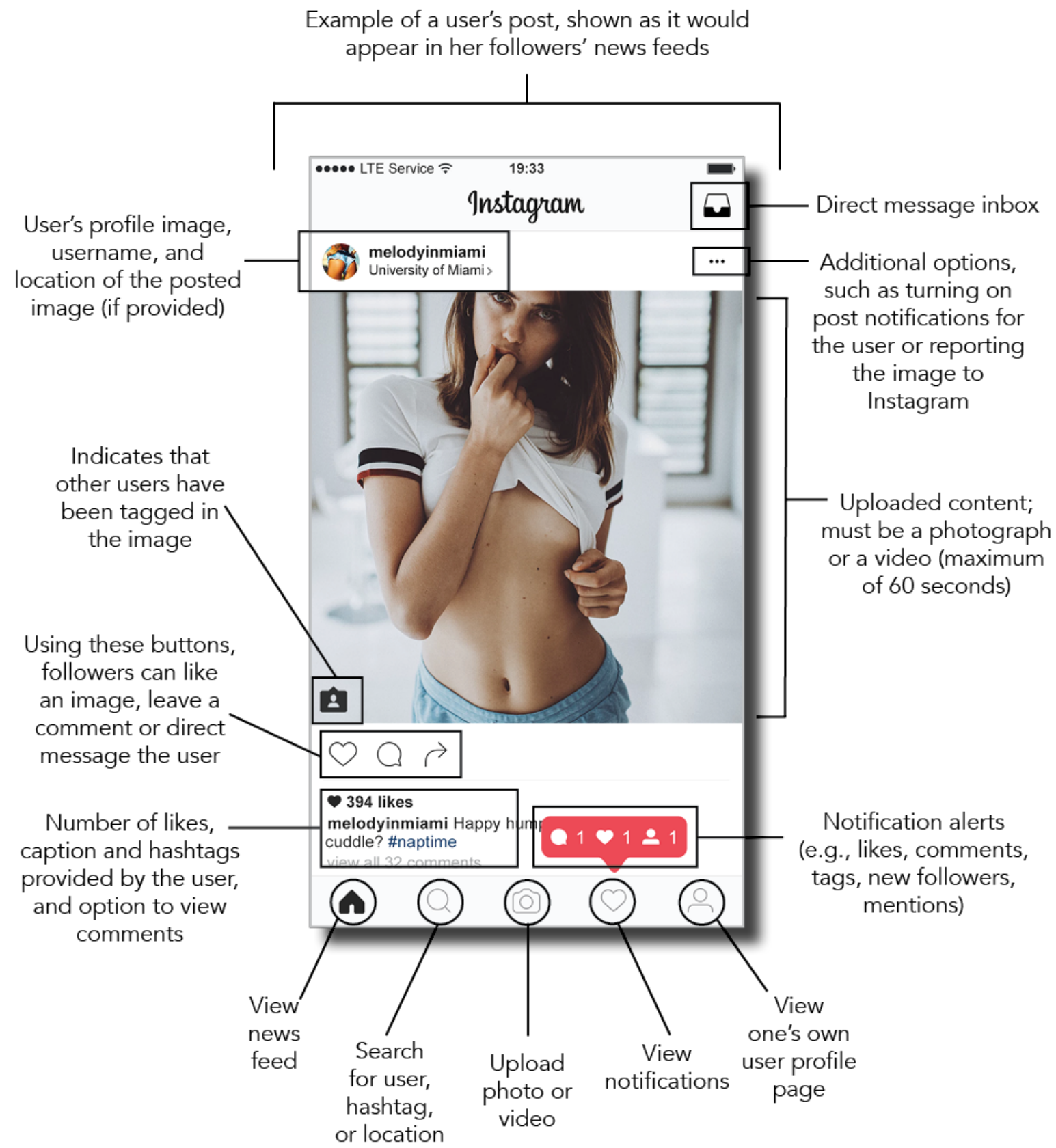


Sampling through Sexualised Instagram Shoutout Pages

To identify influencers, the study began by sampling sexualised Instagram shoutout pages, which are dedicated to soliciting, compiling, and re-posting other users' Instagram photographs, along with tagging the original user-hence, giving the shoutout. A shoutout "is a tool, a lubricant, a virtual currency - the sole purpose of which is to build popularity" (Kids Media Centre, 2018). Shoutouts are intended to show support and give exposure to other users and can substantially increase a user's followers (Jang, Han, \& Lee, 2015). Sexualised shoutouts on Instagram involve taking a screenshot of a female user's posted image on Instagram, uploading the screenshot to the moderated sexualised shoutout page, and tagging the original user in the caption or image. Thus, sexualised shoutout pages are reflective of attention currency within the Instagram platform and provide a systematic entry point in our process of identifying individual women's Instagram profiles that have attracted widespread attention. Figure 2 provides examples of sexualised Instagram shoutout pages, which emphasise heteronormative standards of female beauty and sexuality. For anonymity, these mockups are representative recreations using stock photographs.

Figure 2. Illustrative Examples of Instagram Shoutout Pages
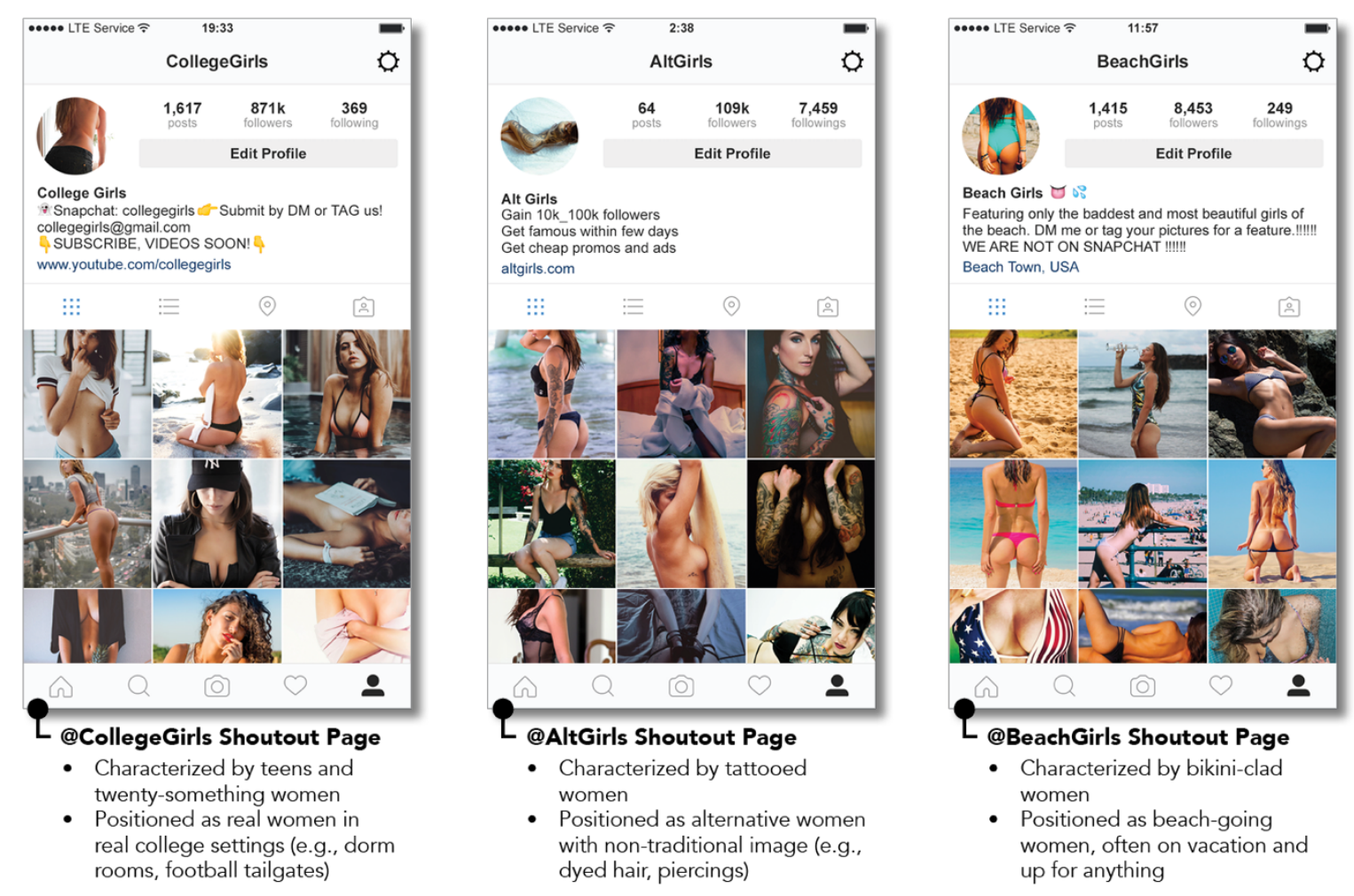
Figure 3 provides an exemplar of the Instagram shoutout process. Images featured on sexualised shoutout pages are typically discovered through three practices: solicitation, submission, or search. First, the moderators of shoutout pages may directly solicit images from women on Instagram, using the direct messaging and commenting features built into the platform. Second, women may submit images directly to shoutout pages, through direct messaging or tagging shoutout pages in their images and captions. As shown in Figure 3, the original user, @melodyinmiami, tags various shoutout pages, including @collegegirls in her image. Her image is then reposted on the @collegegirls shoutout page. Third, images may be discovered by searching hashtags and geotags. For example, the @collegegirls shoutout page moderator may search location-based geotags, like "University of Miami," to discover images or search targeted hashtags like \#collegehotties and \#collegebabes.

Figure 3. Instagram Shoutout Process

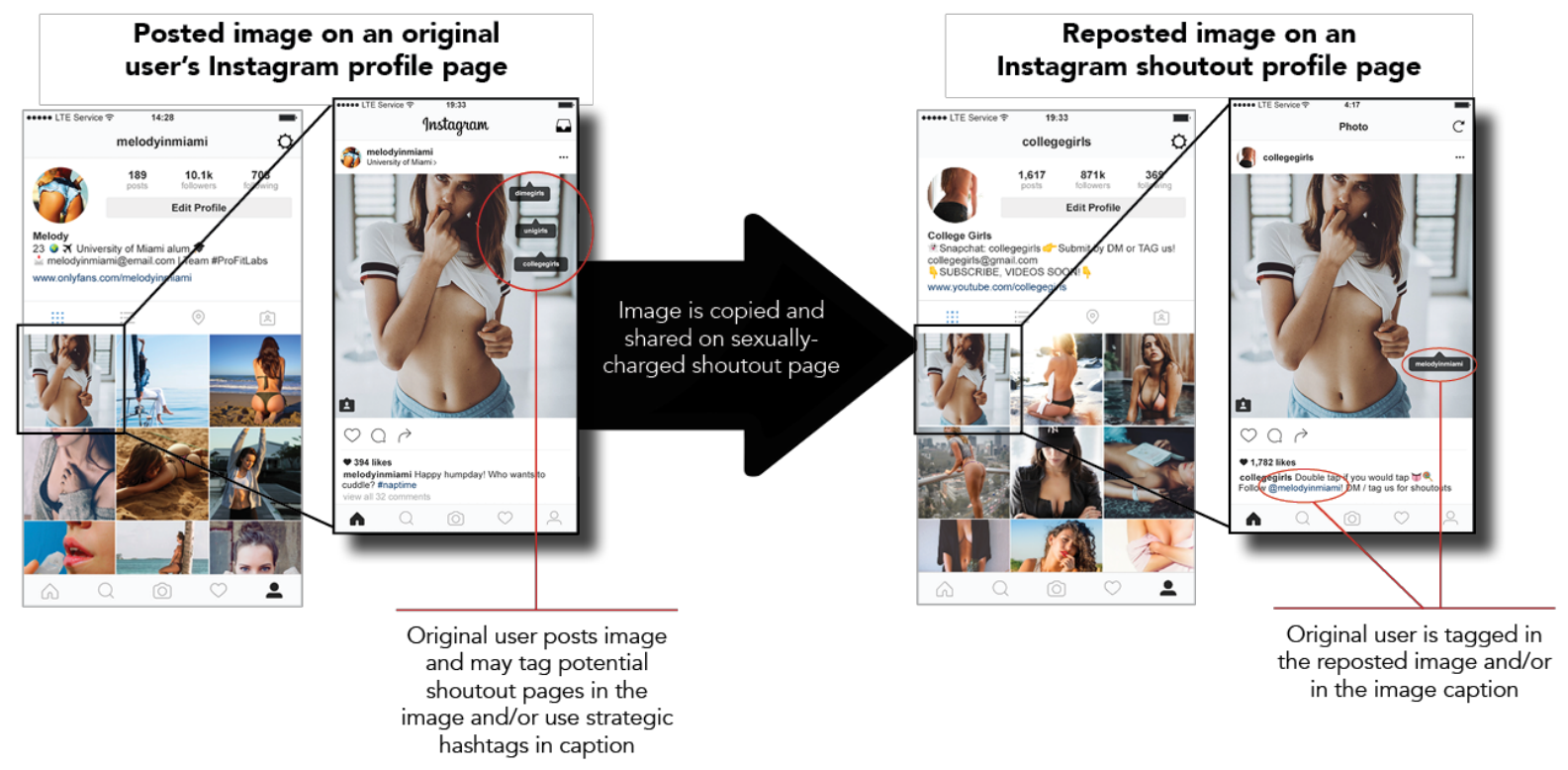

Data collection began by first establishing our sampling frame for sexualised shoutout pages. Through an initial search of Instagram profiles using generic hashtags (e.g., \#girls, \#beauty), shoutout pages were discovered that featured sexualised images of women. Snowball sampling was employed by clicking on related hashtags and suggested profile pages, resulting in a sample of 27 shoutout pages. The sampling frame was limited only to shoutout pages which overtly include language soliciting sexualised images from users (e.g., "DM [direct message] or tag to be featured") and which tag the original user (i.e., the featured 
'model'). Table 1 provides detailed information about each page, including number of followers and profile bio description. Pseudonyms have been assigned to each page, and, if applicable, to tagged users in the text of the bio. While sexualised content is central to each shoutout page, each page has a distinct focal niche or thematic style (e.g., curvy girls, college girls, tattooed girls) - as evident in the exemplary profile mockups shown in Figure 2. The profile bios provided in Table 1 offer evidence toward the diversity of pages represented in our sampling frame.

Table 1. Instagram Shoutout Pages

\begin{tabular}{|c|c|c|c|c|}
\hline $\begin{array}{l}\text { Shoutout Page } \\
\text { Pseudonym }\end{array}$ & Posts & Followers & Following & Profile Bio \\
\hline @RabbitGirls & 70 & $3.7 \mathrm{~m}$ & 67 & $\begin{array}{l}\text { Turn On Post Notifications? _ Where's that Wascally Wabbit? } 4.5 \text { Need } \\
\text { a Promo? DM of }\end{array}$ \\
\hline @ThickGirls & 1,339 & $2.1 \mathrm{~m}$ & 2,999 & $\begin{array}{l}\text { TURN ON POST NOTIFICATIONS = MALE OWNERS = Profile Pic: } \\
\text { @influencer - thickgirls@gmail.com } \$ \text { Follow the backup } \\
\text { instagram.com/boomgirls }\end{array}$ \\
\hline @BoomGirls & 1,542 & $1.5 \mathrm{~m}$ & 1,251 & $\begin{array}{l}\text { BoomGirls | TURN ON POST NOTIFICATIONS - MALE OWNERS - } \\
\text { S4S 100k \& up Send DM SHOP NOW bit.ly/BuyBitcoinGet10FREE }\end{array}$ \\
\hline @QueenGirls & 81 & $1.1 \mathrm{~m}$ & 111 & $\begin{array}{l}\text { Models Dromo Peatures Hot and Elegant Babes } \\
\text { Following and Liking photos }- \text { Contact me at Dm }\end{array}$ \\
\hline @AltGirls & 1,242 & $1 \mathrm{~m}$ & 518 & $\begin{array}{l}\text { Tattooed girls you will love | default @influencer } \\
\text { For a feature please DM us Click the link below for our only fans page } \\
\text { onlyfans.com/altgirls }\end{array}$ \\
\hline @TwerkGirls & 164 & $1 \mathrm{~m}$ & 221 & $\begin{array}{l}\text { You Can't Copy Respect } 100 \mid \text { Paid Promo | PayPal | Trendsetter Display } \\
\text { pic: @influencer Turn On Post Notifications } \\
\text { Intended }\end{array}$ \\
\hline @WildGirls & 24 & $877 k$ & 103 & $\mathbb{b} \mid \bullet$ FOR Promos/Business Inquiries $\bullet$ DIRECT $ڤ \bullet$ DM for Credits $\mathbb{A}$ \\
\hline @CollegeGirls & 1,617 & $871 \mathrm{k}$ & 369 & $\begin{array}{l}\text { Snapchat: collegegirls Submit by DM or TAG us! } \\
\text { collegegirls@gmail.com. SUBSCRIBE, VIDEOS SOON! } \\
\text { www.youtube.com/collegegirls }\end{array}$ \\
\hline @StarGirls & 15,468 & $493 \mathrm{k}$ & 346 & $\begin{array}{l}\square \text { Business \& Promotion Inquiries ONLY: } \underline{\text { StarGirls@gmail.com | we do }} \\
\text { NOT accept submissions. } \\
\text { \#stargirl \#stargirls \#stargirlsonly }\end{array}$ \\
\hline @HopefulGirls & 5,029 & $369 k$ & 378 & $\begin{array}{l}\text { (8) email@hopefulgirls.com | MUST have a photo set in review MUST } \\
\text { have link in bio \& linked to IG (Read the link in our bio) Tag your } \\
\text { photographers www.hopefulegirls.com }\end{array}$ \\
\hline$@$ CutthroatGirls & 336 & $341 \mathrm{k}$ & 2,494 & $\begin{array}{l}\text { Male owner I post, models, dancers and just everyday women all } \\
\text { tagged. Dm for feature inquiries. \#makethecut | pic@cutthroatgirls.com }\end{array}$ \\
\hline @AussieGirls & 964 & $180 \mathrm{k}$ & 180 & $\begin{array}{l}\text { Aussie Alt Models Admins @moderators @ To be featured } \\
\text { \#aussiegirls only! Profile pic features @influencer } \\
\text { www.aussiegirls.com/recruit }\end{array}$ \\
\hline$@$ DimeGirls & 95 & $94.2 \mathrm{k}$ & 1,214 & $\begin{array}{l}\text { (1) Snapchat: dimegirls Be Active } \\
\text { Paid Promos Available Dm Me I'll Rise Up or" dimegirls.co }\end{array}$ \\
\hline @CountryGirls & 1,714 & $72.6 \mathrm{k}$ & 7,386 & $\begin{array}{l}\text { Follower submitted photos } \bullet \text { High quality photos only. Page Model - } \\
\text { @influencer }\end{array}$ \\
\hline$@$ HotGirls & 2,176 & $65.3 \mathrm{k}$ & 1,373 & $\begin{array}{l}\text { cover girl @influencer | Shoutout page only Hottest models } \\
\text { SHOUTOUTS Male administration on Any rude or stupid comments } \\
\text { gets you blocked hotgirls.com }\end{array}$ \\
\hline
\end{tabular}




\begin{tabular}{|c|c|c|c|c|}
\hline @AssGirls & 836 & $48.8 \mathrm{k}$ & 7,361 & $\begin{array}{l}\text { Featuring Tropical Beauty @influencer profile pic Please follow prior to } \\
\text { submitting pics. Follow, like, and comment! Thanks for } \\
\text { following! } \frac{1}{1}-1\end{array}$ \\
\hline @AlphaGirls & 47 & $47.3 \mathrm{k}$ & 220 & $\begin{array}{l}\text { Beautiful Babes Fitness Fashion Models Brands Health } \\
\text { Checkout }\end{array}$ \\
\hline$@$ CoolerGirls & 942 & $40.6 \mathrm{k}$ & 257 & $\begin{array}{l}\text { Welcome to Cooler Girls Daily } \\
\text { DM us a picture and we will post! MERCH \& \& at link below! } \\
\text { coolergirls.com }\end{array}$ \\
\hline @USAGirls & 957 & $24.3 \mathrm{k}$ & 2,470 & $\begin{array}{l}\text { The Hottest Girls Of North America } \bullet \text { Feature? Tag \& Follow } \bullet 18+\bullet \text { Be } \\
\text { Respectful: Hate = Blocked } \mathbb{Q} @ \text { moderator PP: @influencer }\end{array}$ \\
\hline$@$ BadGirls & 254 & $17.8 \mathrm{k}$ & 7,337 & $\begin{array}{l}\text { We BadGirls University Est. } 4.26 .17 \text { \#badgirls } \\
\text { Promo for all baddies } \text { @ocking with us } \\
\text { Upcoming Brand } ₫ 2019 \text { | Modeling/Clothing/Photographym. } \\
\text { cash.me/badgirls }\end{array}$ \\
\hline @DivaGirls & 3,621 & $15.6 \mathrm{k}$ & 2,579 & $\begin{array}{l}\text { We Publish Beautiful Girls From All Over The World. DM Us To Be } \\
\text { Featured } 18+ \\
\text { Website coming soon } \\
\text { twitter.com/divagirls }\end{array}$ \\
\hline$@$ SmokingGirls & 488 & $14.7 \mathrm{k}$ & 1,064 & $\begin{array}{l}\text { Be Confident. You are smoking hot } \\
\text { feature. }\end{array}$ \\
\hline$@$ BeachGirls & 1,302 & $12.4 \mathrm{k}$ & 4,176 & $\begin{array}{l}\text { DM or tag us for a feature! Beach girls daily For business or } \\
\text { promotion DM us BeachGirls }\end{array}$ \\
\hline$@$ BootyGirls & 55 & 9,456 & 993 & $\begin{array}{l}\text { Booty is beautiful everywhere, especially on the beach } 3 \text { All models are } \\
\text { tagged } 9 \Rightarrow \text { Turn on Post Notifications } 2 \text { Leave a comment for a follow } \\
\text { back } \$\end{array}$ \\
\hline @BikiniGirls & 478 & 3,261 & 6,002 & $\begin{array}{l}\text { Bikini Models \& Brands Tag/DM For Feature Must be 18+ } \\
\text { Respect all models/ featured girls | Every Season Is Bikini Season }\end{array}$ \\
\hline @BeautifulGirls & 369 & 1,127 & 4,832 & $\begin{array}{l}1 \text { DM for shoutouts } 1 \odot \text { Page Model: } @ \text { influencer } \bigcirc \text { Featuring } \\
\text { fitness, modeling, fashion, outdoor enthusiasts, athletes, and artist }\end{array}$ \\
\hline$@$ @niGirls & 120 & 382 & 1,017 & $\begin{array}{l}\text { Pics from a college near you! } D \mathrm{Dm} / \text { Tag to be featured Respect the } \\
\text { post be a gentlemen or get blocked! Follow us ! Students only ! }\end{array}$ \\
\hline
\end{tabular}

*Pseudonyms are used for each shoutout page and any identifying information. Relevant acronyms are provided below.

- "DM" = direct message

- "PP" = profile picture

- "S4S" or "SFS" = shoutout for shoutout

Collecting and Refining the Data

Data collection next involved a process of immersion across four months with the 27 sexualised shoutout pages and the development of characteristic vignettes of each page to gain an initial understanding of the nature of each page and observe the posting practices. After the initial observation period, a systematic approach to data collection was taken by downloading ten consecutive images from each shoutout page from a common date into a Google spreadsheet, resulting in 270 individual images across the 27 sexualised Instagram shoutout pages. Videos were not included in the data. Downloaded content for each image included date posted, a screenshot of the image, a permanent link to the image, and image caption. In addition, each of the downloaded images was traced back to the tagged influencer featured in them. The permanent link to each influencer's Instagram profile and her self-provided profile bio was recorded. The data was further refined 
by removing 13 influencers with deleted profiles, 13 influencers with private profiles and 14 duplicates of profiles across multiple shoutout pages.

The data was further refined through analysis of each influencer's profile to gain a better understanding of the monetisation practices, if any. This process included a deep immersion into each influencer's profile - clicking through her images, following external links posted on her Instagram page (e.g., YouTube channel, personal website), noting self-identifying language used in her profiles (e.g. "brand ambassador", "influencer"), and signals of monetisation (e.g., paid partnerships, coupon codes, tagged brands). For each influencer, the first 25 photographs and/or videos were reviewed, including reading through comments, captions, and hashtags on each posted image to determine the nature of the influencer profile. Influencers' profiles with no evidence of commodification were removed ( $n=58$ ). Thus, the final set of Instagram profiles for analysis included 172 influencers. The content posted on each of these 172 influencers' profiles served as the data for analysis. This included images, hashtags, image tags, captions, external links (e.g., YouTube, e-commerce site), and comments. Each influencer was assigned a pseudonym for anonymity.

Analysing the Data

This study employs a dual qualitative approach of visual and textual analysis of Instagram posts from female influencers who engage in sexualised labour. In media analysis, analysing text and imagery together is important to identify connections or deviations between the two elements (Elliott \& Stead, 2018; Liu et al., 2015; Scollon \& Scollon, 2003; Kress \& van Leeuwen, 2006), recognizing that "images are simultaneously independently organized, structured messages but are also connected to the written text" (Elliott \& Stead, 2018, p. 27). In other words, what Instagram influencers show in their images may reinforce or contradict what they say in their captions and/or comments. Visual and textual data from the influencers' profiles were analysed using an iterative, hermeneutical approach (Thompson, 1997). Each Instagram post was analysed independently, searching for meanings and patterns, rather than just casually reading the data (Braun \& Clarke, 2006). This encompassed an analysis of the visual content (e.g., photograph), the text (e.g. captions and hashtags) and interactive affordances (e.g. likes and comments) of each post. Then, the posts were analysed across influencers to identify patterns and related back to existing literature to develop insights about how sexualised labour is employed to monetise attention on Instagram.

Following the initial immersion period, the data were analysed through a combination of deductive a priori and inductive open coding that was driven by constant comparison looking for similarities and differences (Fereday \& MuirCochrane, 2006). Data were first sorted into inductively derived categories of influencer labour (e.g., affiliation-based influencer labour, access-based influencer labour, or evidence of both). In line with Elliott and Stead's (2018) visual semiotic 
approach to analysis, we considered the following factors: composition, or how the elements in an image are arranged; representational meaning, or how the elements of an image interact; modality, or the credibility of an image; and interactive meaning, or the relationship an image fosters with its viewer. As the analysis developed, patterns emerged offering insight into how sexualised labour is performed within these. Specifically, to analyse sexualised labour, three a priori codes (i.e., aesthetic labour, emotional labour, sexualisation) and one emergent code (i.e., connective labour) drove the analysis. For aesthetic labour, embodied aesthetic attributes were coded, such as prosumers' physical poses (e.g., kneeling, holding breasts in hands), props and clothing (e.g., food, drink, bathing suits, lingerie), location (e.g., in a bedroom, at the beach, in a kitchen, at a gym) and other stylistic devices (e.g., stylized makeup, tattoos, dyed hair). In coding for emotional labour, the analysis considered how prosumers engaged with their followers (e.g., captions, comments, emojis), the emotional sentiment of interactions (e.g., defensive, gracious, positive, upbeat), and the frequency of interactions (e.g., nonresponse, immediate response). During the analysis process, connective labour emerged as a required practice to mobilise sexualised labour, which was coded by examining prosumers' use of digital affordances, including lowlevel functional features of the platform (e.g., image tagging, hashtagging) as well as relational facilitation (e.g., contactability, redirecting) (Bucher \& Helmond, 2016). In line with our conceptualisation of sexualised labour, the analysis was directed by considering the interconnections between these forms of labour.

The dataset was managed via Google sheet. The analysis progressed by reviewing the influencers' profiles, looking for outlier cases, developing categorisations and refining the coding scheme. In line with our conceptual framework, which we present in the next section, the 172 influencers were placed in etic categories of influencers - hopefuls (21), boasters (45), engagers (26), boosters (30), and performers (50). Notably, a key challenge in our data is its ephemerality. Instagram's policies prohibit nudity or sexual content from being shared on the platform; however are enforced haphazardly. In some cases, shoutout pages and/or influencers' profiles were deleted by the platform due to policy violations. Some shoutout pages and influencers, included in the original sample, were later deleted by the platform during the period of analysis. Rather than a permanent and static collection of content removed from its social media platform, our data exist online, in its natural state - enabling one to dip in and out of the data for analysis. Indeed, our dataset was (and is) a dynamic one; providing a naturalistic approach to the ongoing understanding of how women perform sexualised labour in a digital prosumption environment. 


\section{Research Findings}

We draw upon the data to examine the articulation of sexualised labour in the prosumer and digital context of Instagram. Our emergent framework in Figure 4 is derived from the data and illustrates how sexualised labour supports selfcommodification, which unfolds on a continuum from non-monetised and low attention practices to monetised and high attention practices. Along the continuum, monetisation and attention relate to sexualised representations in different ways. Although this sexualisation is largely bounded by 'porn chic', it ranges from what could be deemed 'softer' or more 'cheesecake' shots (Meyerowitz, 1996) with references (conscious or unconscious) to pornographic convention to more overt pornifed images which are often difficult to differentiate from mainstream commercial pornography with direct links to commercial sex industry sites (e.g. web cams, strip clubs).

Figure 4. A Framework of Self-Commodification through Sexualised Labour

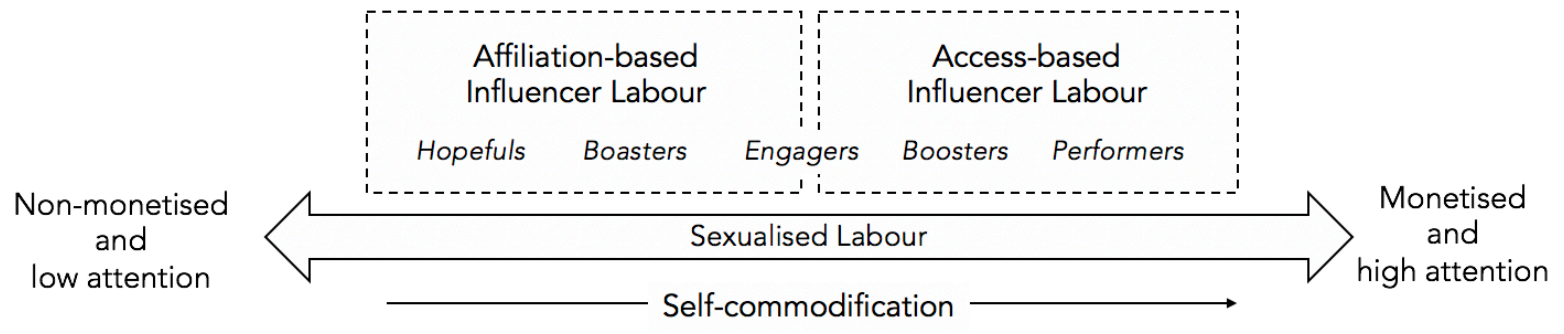

Non-monetised and low attention practices encompass more affiliationbased influencer labour, which works toward gaining a formal affiliation with an established brand in the marketplace. Affiliation-based influencer labour seeks to gain and hold the attention of an external brand via sexually suggestive and playful engagements with social media followers that are mobilised through increasingly subtle digital affordances. In contrast, monetised and high attention practices reflect more access-based influencer labour, which works towards establishing one's identity as a brand of value in the marketplace. Access-based influencer labour supports self-marketed ventures via sexually explicit and strategic engagements with attentive social media followers through employing increasingly sophisticated digital affordances. Such ventures can include producing tangible products (e.g., clothing line, skincare), offering personal wellness services (e.g., makeup artistry, personal training), and accessing exclusive and personalised sexual content (e.g., personal camming website, private Snapchat membership).

Our findings offer quite a different reading of sexualised labour, which to date has been bound within the confines of a more traditional organisational setting (e.g. retail store, restaurant) with workers employed under more secure conditions (e.g. receiving a salary/wage and structured by organisational policies and 
procedures). Drawing on evidence from the data, we next present how emotion, aesthetics and 'porn chic' sexualisation mesh to articulate performances of sexualised labour across five identified forms of influencer labour. These encompass hopefuls, boasters, engagers, boosters, and performers. Connective labour emerges as a required element to mobilise sexualised labour, encompassing practices, skills and knowledge employed to successfully embody and negotiate the performance of sexualised labour for attention and monetisation purposes. In our study and its social media context, this was elaborated in the form of digital affordances.

Hopefuls

Hopefuls are aspiring influencers who seek to be affiliated with brands and perform sexualised labour to be discovered and gain the attention of potential brand partners and followers, without monetary compensation. Figure 5 provides exemplary posts from hopefuls. Although each woman's profile stylistically appeals to a particular lifestyle and related brands, the same 'look' needed to succeed as an influencer is reiterated throughout the data. This look is conveyed primarily through poses, gestures and stylistic choices, beginning at hopefuls who emulate a sexualisation that becomes increasingly explicit, niche and disembodied along the continuum toward performers. Throughout our data, influencers consistently pose in ways that highlight body parts, wear tight, short and revealing clothing and employ gestures such as gently pulling their hair, touching their parted lips and simulating undressing. Combined, these efforts both draw upon and reproduce a recognizable soft 'porn chic' aesthetic (Dines, 2015; Harvey \& Robinson, 2007). For instance, in Figure 5, Jessica, Liz, and Valerie each demonstrate the same physical pose of popping their hip to the side to accentuate bodily curves and provide the illusion of rounder buttocks and a smaller waist. For hopefuls, these 'porn chic' aesthetic signals are often more subtle and candid. For example, in a post Jessica reveals her body in a bikini but chooses to take a selfie in a bathroom mirror as opposed to posing in a more stylised manner at a pool or beach.

This sexually suggestive aesthetic is reinforced through interactions with social media followers governed by feeling rules of positivity, conviviality and playfulness, thus mirroring the emotionality noted in previous research of sexualised labour within interactive services (Warhurst \& Nickson, 2009). Hopefuls offer upbeat and somewhat cliché captions (e.g., "that view tho", "happy hump day"). These phrases are representative of a type of 'organisational shorthand' in the Instagram environment, and similar to previous research on workplace clichés (e.g., 'work hard, play hard'; Anderson-Gough, Grey, \& Robson, 1998), they reflect uncertainty of the individual-in this case, hopefuls who are trying hard to gain attention. Hopefuls reinforce sexual suggestiveness through emotionality as they appeal to followers to gain more attention. For example, one hopeful, Morgan, enters a teen model search for a clothing brand based on Instagram 'likes' and calls upon her 
Figure 5: Examples of Hopefuls
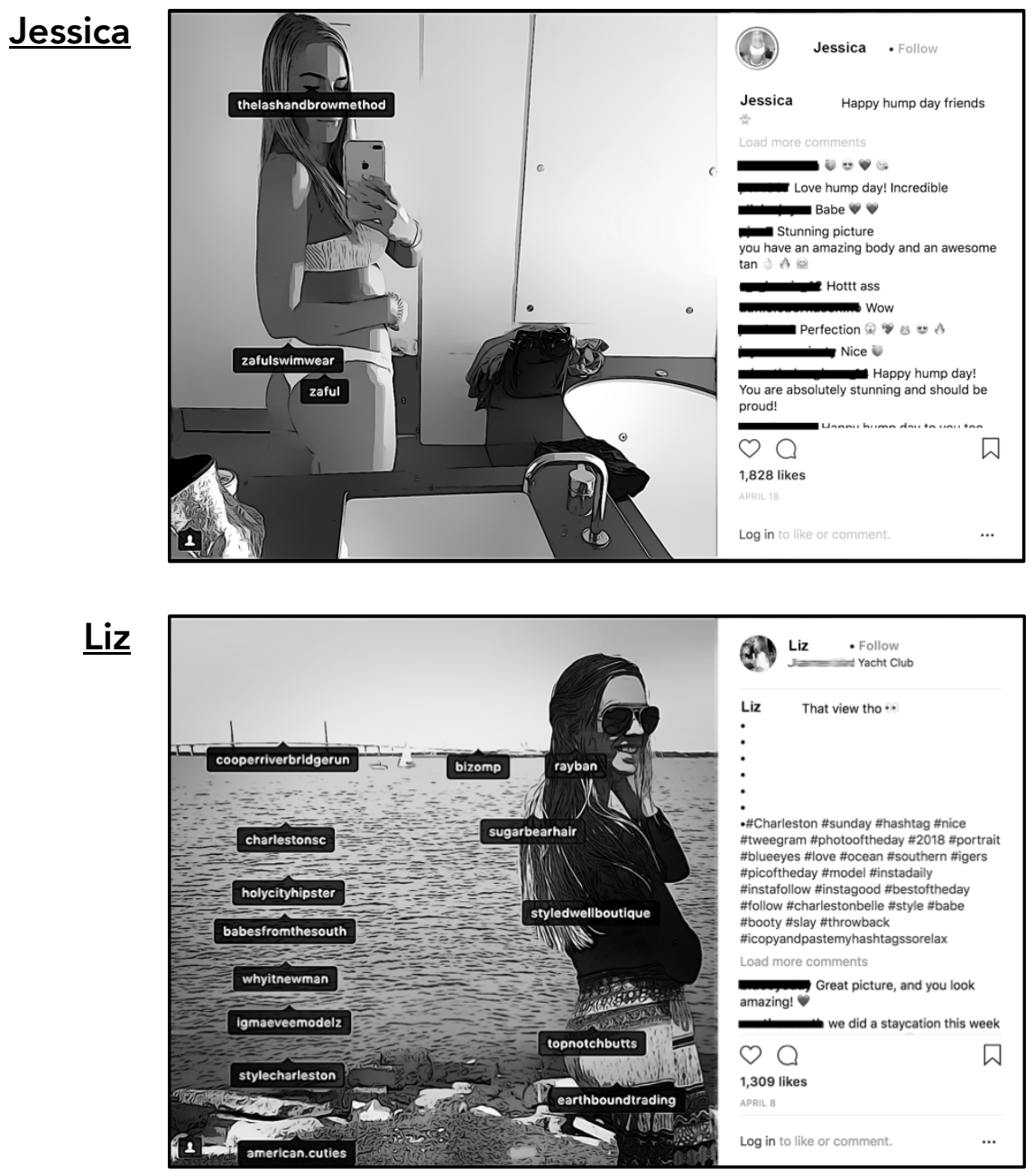

$\underline{\text { Valerie }}$

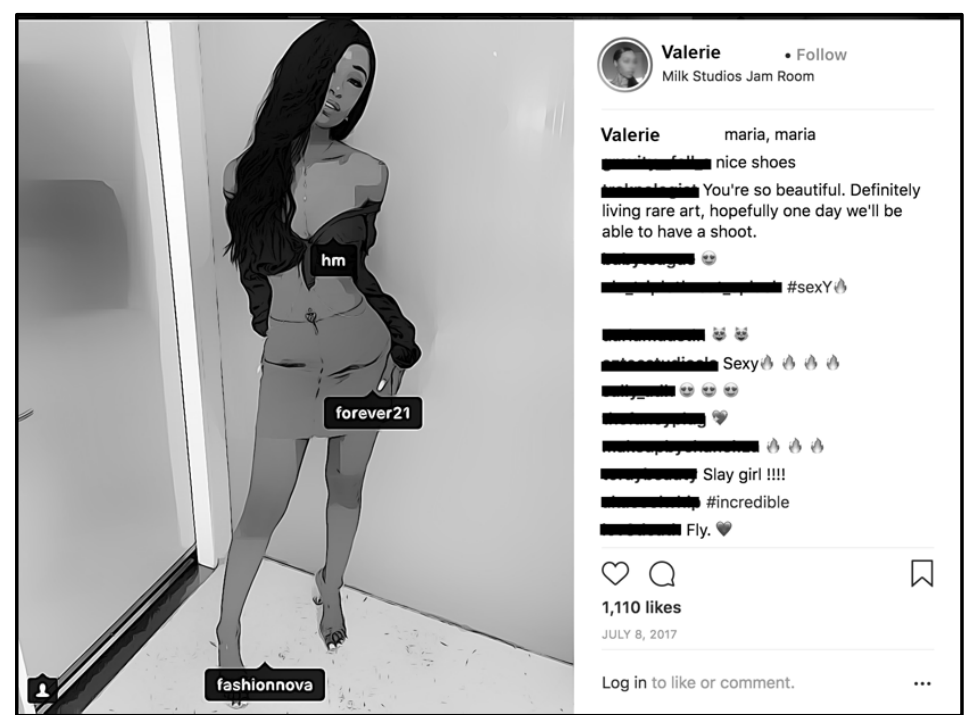


followers to like her photo, promising to post more sexually suggestive images if she wins (e.g., "LIKE WHAT YOU SEE AND WANT MORE? PLEASE GO LIKE THIS PICTURE TO HELP ME WIN MODEL OF THE WEEK!!!! PQP९९)"). Competitions such as this convey viability of the sexualised aesthetic and demonstrates the extent to which others (e.g., followers, brands) support the aesthetic. In our data, we also begin to see how brands solicit women to perform sexualised labour on their behalf. For example, on Liz's image in Figure 5, four different clothing and swimwear brands comment on her image-each complimenting her and requesting that Liz send a direct message ("DM") to the brand to get free products or become a brand ambassador. Yet, even as brands seek to exploit influencers' sexualised bodies, the onus for maintaining burgeoning attention remains on hopefuls.

Thus, aesthetics, emotions and 'porn chic' sexualisation mesh in a performance of sexualised labour, albeit in a more amateur manner for 'hopeful' influencers. In turn, these are mobilised through connective labour that employs the digital affordances of Instagram to gain the attention needed for monetisation potential. For hopefuls, this manifests in the sheer magnitude of tagging they undertake with a view to creating as many affiliations as possible. For example, in addition to tagging a geolocation and including 27 general hashtags in her caption, Liz (see Figure 5) image tags 13 other Instagram profiles, including clothing brands, beauty products, shoutout pages, and tourist destinations. None of these 'partners' financially sponsor her photograph; rather, she tags them to maximise attention on the platform - to be discovered, gain more followers, and get more likes. Indeed, hopefuls engage more overtly in this type of connective labour in an effort to mobilise their sexualised aesthetic and emotional labour-in this case, to build potential attention on the Instagram platform. However, this provision of free advertising for brands by hopefuls is sexually objectifying. That is, in order to get noticed by potential affiliate brands, hopefuls subscribe to culturally prescribed female body ideals as the primary object of attention (Fredrickson \& Roberts, 1997). Yet, as hopefuls have only just begun down the path of attracting attention, their labour receives no monetisation. As Mears (2014) observes, the subjective experience of being aesthetic comes with a seeming pleasure and empowerment that can seduce workers to labour under poor wage and benefit conditions. Similarly, our research highlights that 'hopeful' digital influencers consistently perform sexualised labour on behalf of brands for no financial incentives. Hence, we can see how women's unpaid labour in digital spaces adds value to economies in unacknowledged yet meaningful ways.

\section{Boasters}

Boasters encompass influencers who have informal affiliations with brands and perform sexualised labour to capitalise on this initial brand attention without monetary compensation or with very precarious referral-based compensation. Boasters are often recipients of branded freebies, free product trials, and coupon 
Figure 6: Examples of Boasters

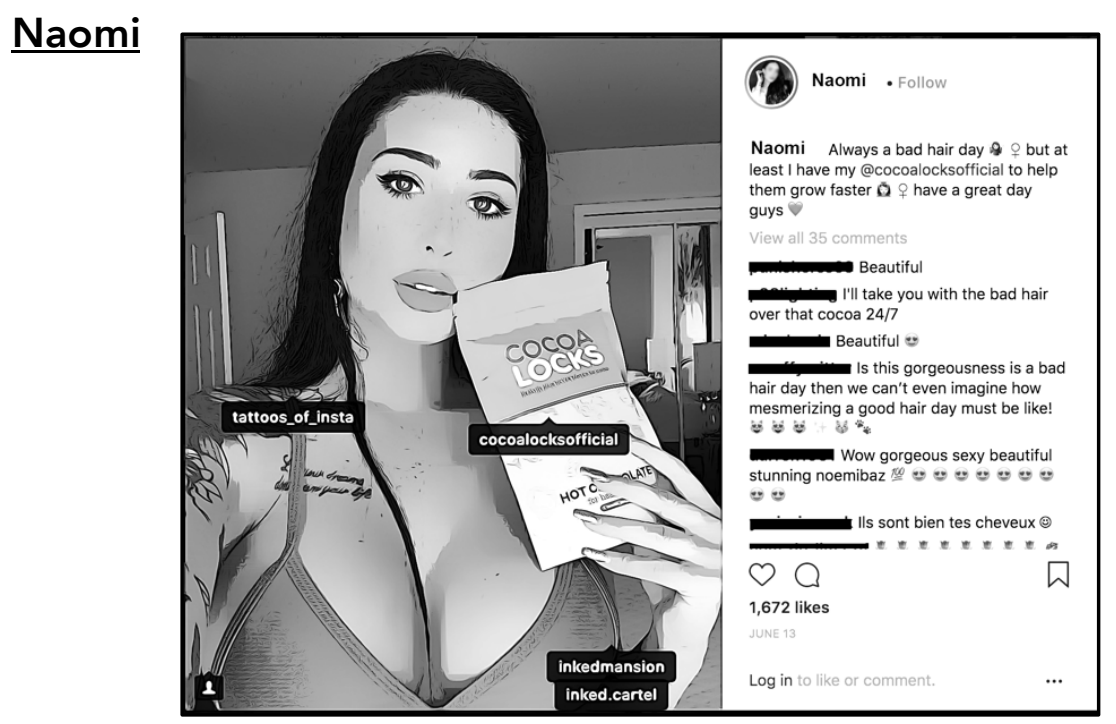

Shayla

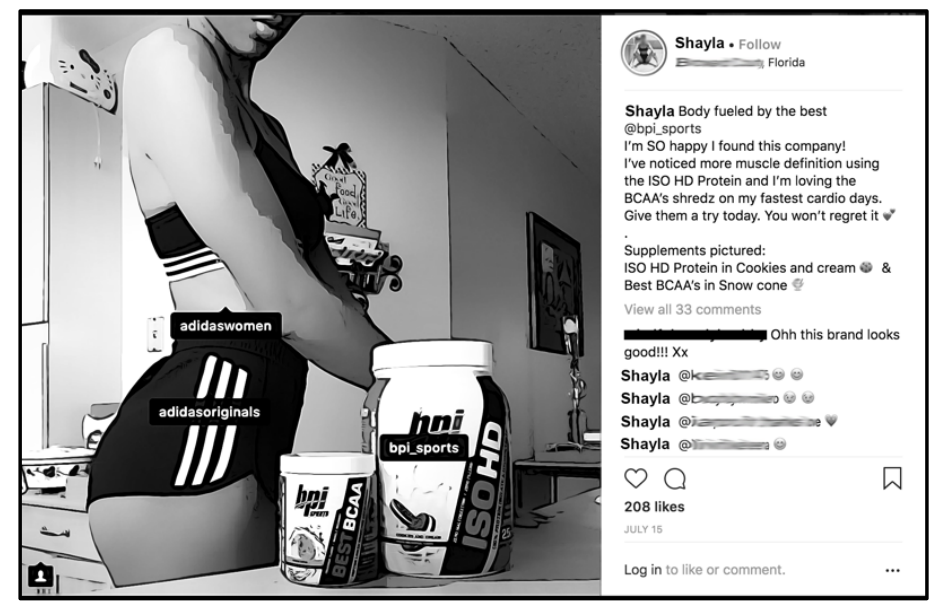

$\underline{\text { Sarah }}$

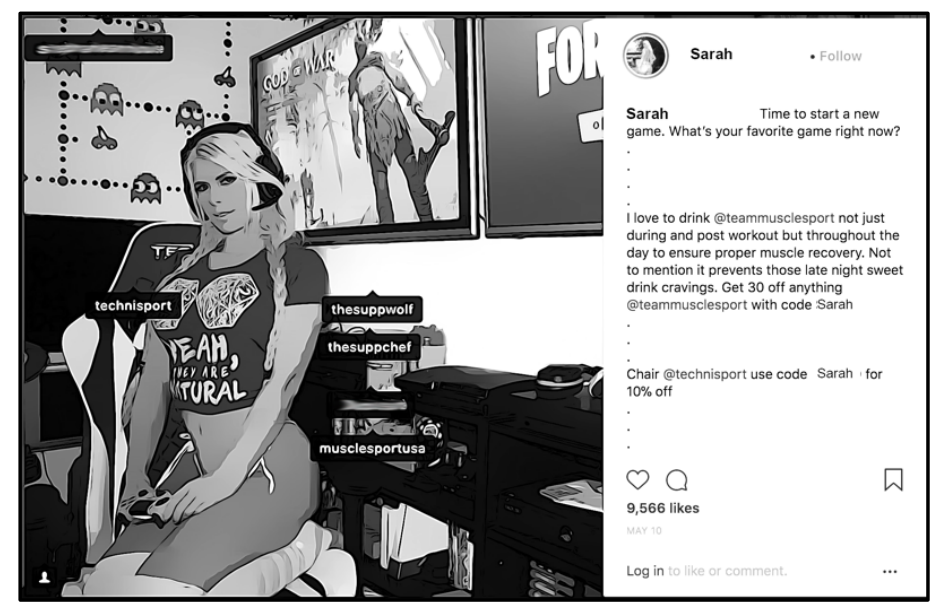


codes-all which serve to promote the external branded product yet fail to provide (meaningful) monetary compensation for the influencer. Still, influencers boast about these branded affiliations, which are heralded as authenticating and legitimising partnerships in the digital realm of prosumption. Thus, boasters rely heavily on aggrandizing brand affiliations in their images. Figure 6 provides exemplary posts from boasters.

Again, for boasters the 'look' of porn chic was reproduced in their posts. Products are used conspicuously as props and often act to support an aesthetic of sexual suggestiveness. For example, Naomi uses a hair product package as a prop, gently resting it against her mouth; however, the central focus of the image is not her hair-but her breasts. Indeed, boasters' aesthetic labour involves focusing the image on the product while still drawing upon 'porn chic' sexualisation to garner attention. These overt brand promotions are risky as followers may perceive them as inauthentic (Kozinets, et al., 2010); however, our data suggests boasters maintain the attention of the audience through the replication of 'porn chic' poses and gestures, such as squatting, gently propped up on their shins, placing their hands strategically between their legs and drawing the viewer's attention there (see Sarah, Figure 6). The products promoted through boasters' sexualised labour are consistent across influencers in our data and primarily fall into categories of clothing and fashion accessories, nutrition supplements, and skincare and beauty products. Collectively, these products highlight how the influencers' labour is sexually objectifying; selling products that reinforce ongoing effort to produce an idealised body and promote habitual body monitoring, body shame, and internalisation of the thin ideal. Thus, boasters' curated bodies are commodified to promote and sell products directed toward maintaining a particular sexualised aesthetic.

For boasters, this aesthetic labour meshes with emotional labour to create a more niche appeal, akin to traditional market segmentation. For example, Shayla (see Figure 6) crafts a fitness-oriented niche, promoting products like Bang Energy drinks and BPI Sports protein powder. Yet knowing how to successfully get attention and engage with her audience to promote this highlights challenges. In contrast to a 'look' and standards of interaction that are managerially mandated to appeal to the local context and consumer tastes for a given organisation (Otis, 2011), here the individual influencer is responsible for appealing to the senses of their potential 'customers', namely audience of brands and followers. For instance, Shayla appeals to her customers choosing niche hashtags that both reflect her physical appearance and have the potential to connect with women like herself, such as \#fitblackqueens and \#melaninpoppin. In navigating this self-management, certain 'floating norms' (Mears, 2011) come to dictate how influencers gain attention on Instagram. One such norm relates to influencers engaging frequently with their audience by responding to all followers' comments. In doing so, they demonstrate they are fulfilling an expectation about the intimacy that is to be created with their followers (Abidin, 2015). One boaster in our data, Ellen, even 
offered a YouTube tutorial on how to engage with followers, stating "it doesn't have to be super complicated stuff, you know, people compliment you and just say 'thank you' or 'oh love you' ... It's something so small that really helps out a ton on your pictures." By responding frequently to followers, boasters are able to exploit the Instagram algorithm. As Ellen notes, for boasters, it is "vital to reply to your comments because it shows more engagement on your picture." Posts with more engagement (e.g., comments, likes) are deemed more attention-worthy by the platform and thus more likely to be discovered. These frequent, intimate engagements moreover function to amplify the sexually suggestive aesthetics of boasters, such as Shayla's disembodied representation that focuses on her breasts, stomach and buttocks, highlighting the sexual objectification so prolific across the boaster data whereby women are positioned as objects alongside the products they promote.

Like hopefuls, connective labour works to mobilise this aesthetic labour, emotional labour and 'porn chic' sexualisation for boasters. Here, the digital affordances of emojis come to play a critical role. For a boaster, knowing which emojis to use to convey an aesthetic of sexual suggestiveness alongside a playful style of emotional engagement is critical to for getting attention. Emojis are graphic symbols that represent facial expressions, feelings, concepts, and ideas and are employed in nuanced and subtle ways beyond a positive-negative binary to craft intimacies with their audiences (Kralj Novak, Smailovic, Sluban, \& Mozetic, 2015). For instance, in responding to comments, Shayla uses distinct variations of winking

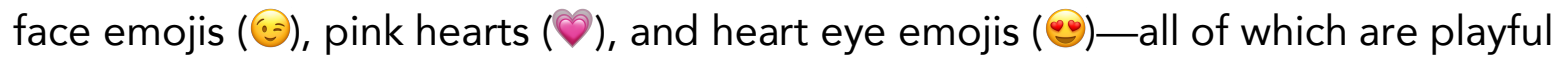
but subtly flirtatious while giving a sense of customised intimacy in each unique response.

Yet, with increased attention, comes a rise in sexual harassment for boasters. Digital media reduces inhibitions and yields more intimate exchanges, given its lack of nonverbal cues and asynchronous nature (Walther, 1996). Followers may share comments they would be unlikely to make in face-to-face settings. Boasters receive sexually aggressive and objectifying comments, yet rather than ignoring them, they employ the same positive, upbeat feeling rules by responding with playful emojis (e.g., laughing emoji) and/or use digital shorthand like "lol" (i.e., laughing out loud) and "haha" to signify humour. Our data show that strategies like reprimanding can risk fallout from followers. For boasters whose relationships with brands are highly precarious commission-based promotions, the risk of losing further 'partnership' opportunities is high. Consequently, hashtags come to play an important reinforcing role in connective labour, with boasters using hashtags strategically and sparingly by limiting them to affiliated brands and their 'niche'. For example, Sarah hashtags her image with gaming oriented hashtags (e.g., \#gamer \#godofwar \#playstation \#xbox \#fortnite) and brand specific hashtags (\#teammusclesport) that focus her affiliations and attention gaining efforts. Similarly, having coupon codes for the brands promoted act as a signal to followers and other influencers that 
sexualised labour can 'pay off' (e.g., getting freebies) while masking that monetisation is still largely absent for boasters.

\section{Engagers}

Engagers are influencers who are formally affiliated with brands and perform sexualised labour to maintain the attention of the brand with monetary compensation. They straddle the boundary between affiliation-based influencer labour and access-based influencer labour. For many engagers, they are building their own person-based brand (Turley \& Moore, 1995), by which they leverage their popularity and attention to establish formal, monetised partnerships with external brands, products, events, and services. Relative to hopefuls and boasters, engagers represent a move toward a highly choreographed and staged aesthetic, still relying on porn chic aesthetics but with a greater emphasis on cultivating a perceived aspirational lifestyle rooted in this modality of sexualisation. For example, in Figure 7, Tanya's sponsored post pairs porn chic gestures (e.g., lips parted, hair-pulling), poses (e.g., hip popped to accentuate curves), and clothing (e.g., cleavage bearing white swimsuit) with a glamorous, luxury vacation paid for by a cosmetics brand. The implicit suggestion is that 'porn chic' sexualisation is a means to pursue an aspirational jet-setting lifestyle. Engagers' images appear candid, but in fact, are planned and professionally captured. This "plandid" approach is common among celebrities, who create highly planned content meant to appear spontaneous (Cheng, 2017) and mirrors the type of snapshot aesthetics prominent in advertising for consumer lifestyle brands (Schroeder, 2011). This mirrors previous work suggesting freelancers engage in ongoing production of 'personality' as a component of aesthetic labour (Entwistle \& Wissinger, 2006); however, our findings suggest engagers move beyond personality to craft aspirational lifestyles, rooted in a modality of sexualisation.

Engagers' heightened attention (e.g., millions of followers) coincides with a further increase in aggressive harassment and objectification (e.g., sexual solicitation, physical threats). For instance, on Anna's image (see Figure 7), a follower comments, "Its damn.... i wanna a fuck u... darling... your ass is really very sexy.... my penis is finding $u$ to have a sex." Unlike boasters, engagers do not respond to such comments; however, they do not remove them either. The intensity, volume and public nature of this harassment is quite different to those experienced in offline service settings by customers and colleagues (Adkins, 1995). Anyone who opens Instagram can harass influencers. The digital platform heightens contactability (e.g., commenting, direct messaging) and perceived availability as the influencers' images are always available to viewers for their consumption. Thus, engagers' aspirational sexualised lifestyle depictions coupled with seemingly constant availability amplifies sexual objectification and vulnerability to harassment. The notion of being 'at work' is tenuous for engagers who experience constant and inescapable interactions with followers without the support of employer 
Figure 7: Examples of Engagers

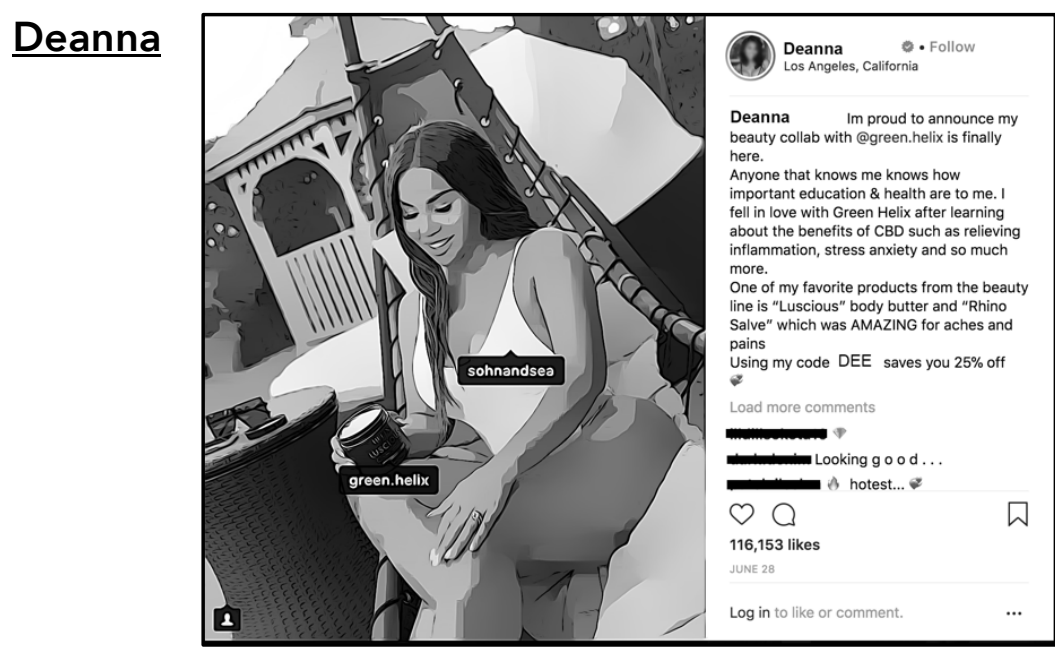

$\underline{\text { Tanya }}$

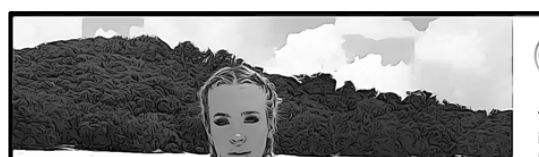

(2) Tanya O. Follow

Tanya Sad to leave this gorgeous island $\uparrow \sum$ but so excited to get home to spoiling us this weekend \#trippinwithtarte \#rethinknatural

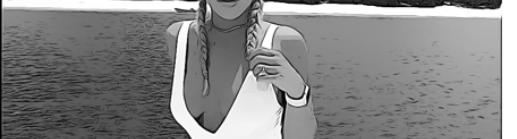

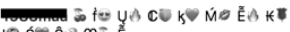

christine_cerv 99,000

ristine_cerv 99,000 liker lol that odd number was driving me insane ... love u $\mathrm{e}$ number

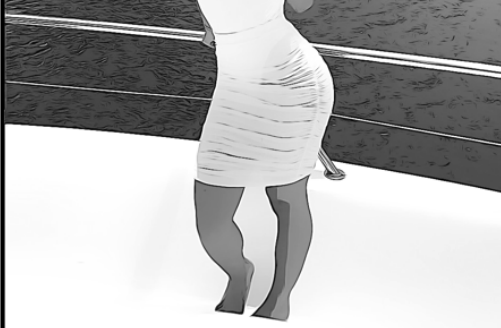

You are goals

What hot

Oh wow, you're gorgeous!

تص

$0 \mathrm{O}$

357,642 likes

Log in to like or comment.

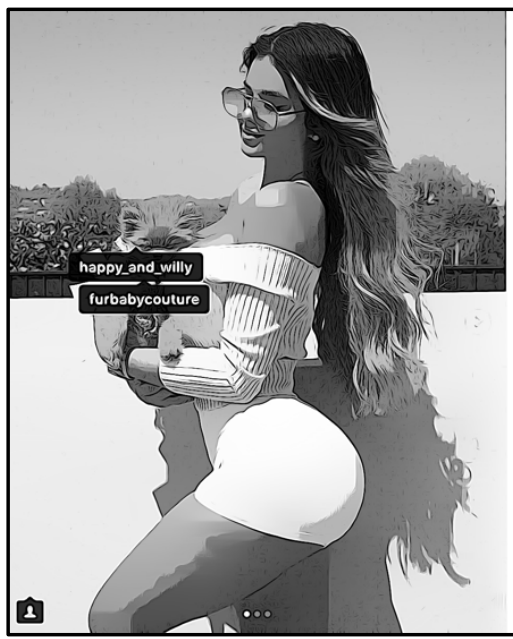

(8) Anna

Anna Follow Aald partnership with furbabycoutur

Anna Thank you for this beautiful dress @furbabycouture for my a little princess

Load more comments

What a cute doge Very good sexy i like To

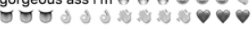
You have the most cutest dog in the whole world

Drice

Jowan\#

U

Como me gustaría ser esa

O

284,951 likes

MAY 10

og in to like or comment 
intervention. Influencers are solely responsible for these interactions and must determine their own guidelines to evaluate which responses are appropriate on a case-by-case basis.

For engagers, aesthetics, emotions and 'porn chic' sexualisation mesh as sexualised labour that encompasses a lifestyle performance. Connective labour mobilises this through digital affordances designed to persuade followers that they could achieve a similar lifestyle by purchasing the products featured in engagers' formalized paid brand partnerships. For example, engagers in our data frequently have 'verified' Instagram accounts-denoted by a blue check mark symbol and meant to authenticate "well-known figures and brands" with "a high likelihood of being impersonated" (Instagram, 2018). This signal communicates that the influencer has 'made it', capturing the attention of brands and establishing formalised partnerships that are promoted to legions of followers. Engagers such as Deanna both legitimise and mobilise their sexualised labour by using hashtags such as \#sponsored and \#ad through which she is able to position her relationship with a brand as a 'collaboration' (see Figure 7). Thus, engagers monetise their sexualised labour by capitalizing on opportunities to merge their carefully crafted lifestyles with sponsoring brands - and in turn, endorse a pathway to monetisation that relies on self-objectification.

\section{Boosters}

Boosters are influencers who promote access to self-marketed products and perform sexualised labour to exploit the attention of social media followers for monetary compensation. That is, boosters mark a shift toward access-based influencer labour as they create and promote their own products or services, such as swimwear, clothing, makeup, sunglasses, and fitness guides, among others. Figure 8 provides exemplary posts from boosters.

In the case of boosters, the female influencer acts as the face of her own brand, rather than performing sexualised labour to promote external brands. Boosters' aesthetic appeal employs more explicit elements of porn chic, with their own personal products used as props. In line with previous work on influencers (Abidin, 2016b), our data suggests considerable work goes into the behind the scenes staging of boosters' images-meant to highlight the product for sale while relying on particular aesthetics to grab the viewers' attention. For example, Jade's image highlights her artwork, both in foreground and background, but notably alongside her cleavage. Aesthetic labour involves a constant awareness and attentiveness towards one's body, even outside of work (Entwistle \& Wissigner, 2006). Similarly, our data suggests influencers are always thinking about and working upon their bodies. This is apparent among boosters as many of them sell curated fitness regimens and diet plans used to 'achieve' their physical appearances. These boosters frequently post images and videos of themselves in the gym, actively showing the 'work' they do to achieve their look while 
Figure 8: Examples of Boosters
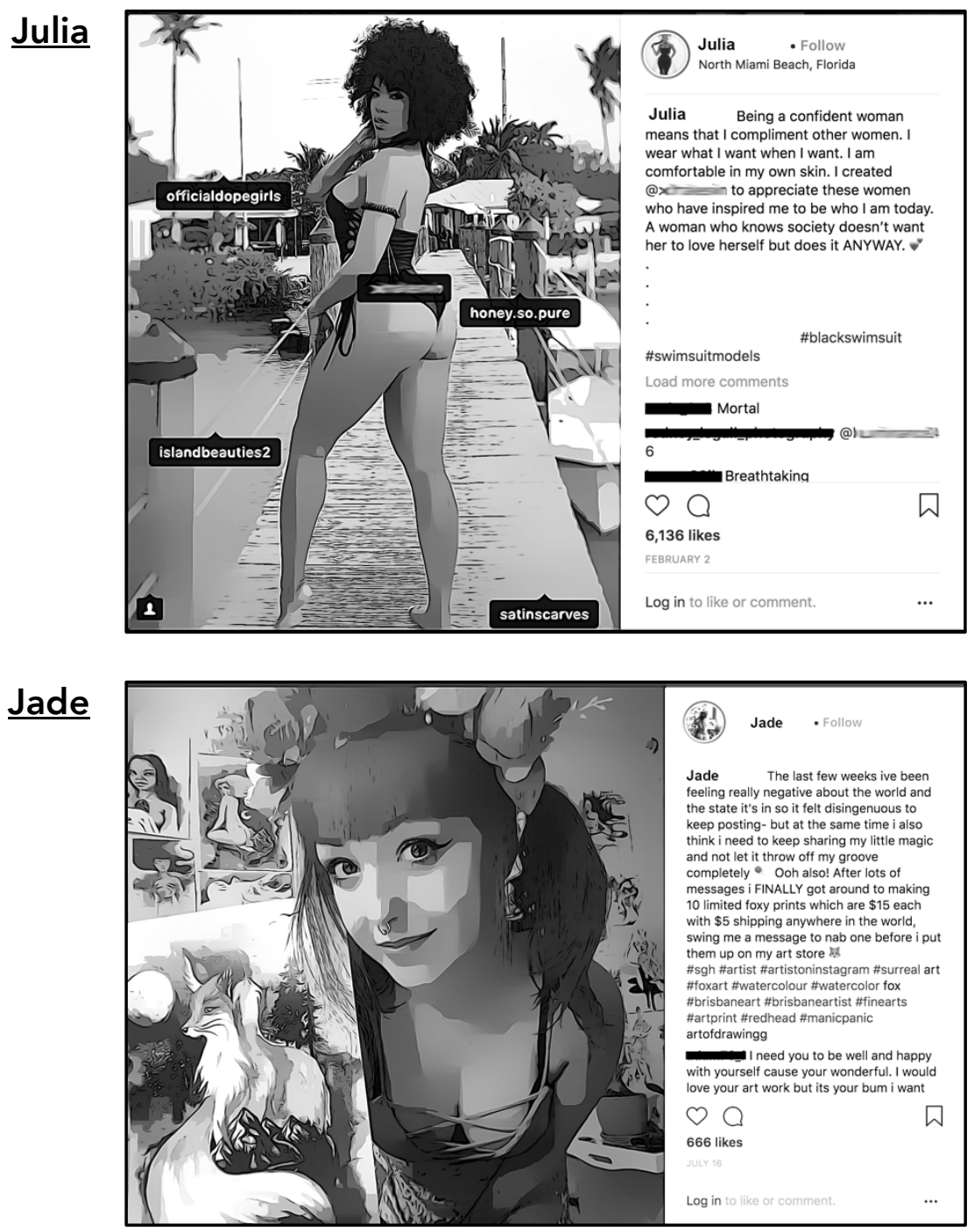

Stephanie

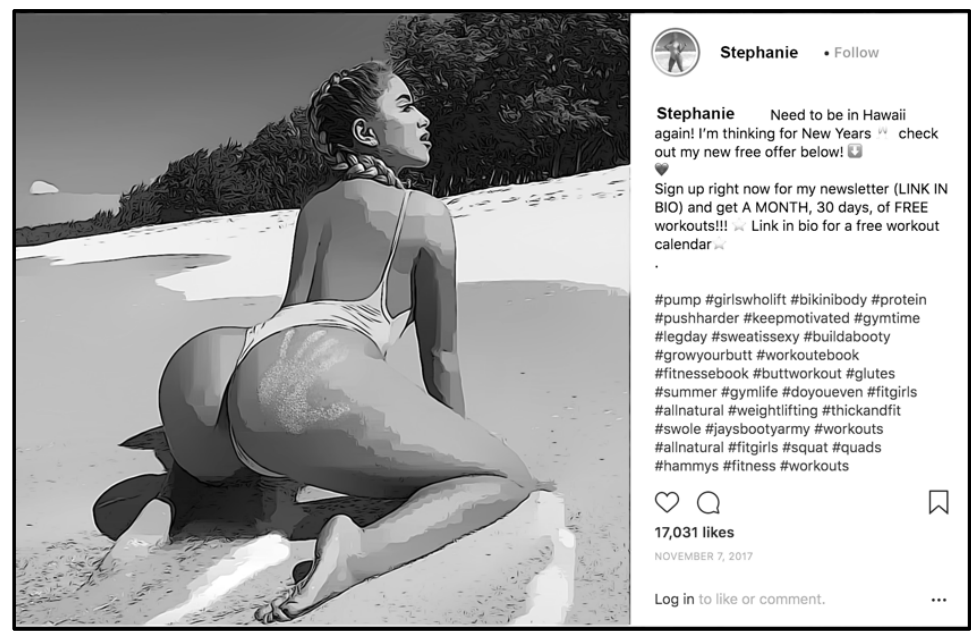


simultaneously promoting the product (e.g., fitness guide) for sale. Still, boosters are distinct from health and wellbeing influencers, who might focus on expanding healthy food choices and encouraging exercise in moderation (Vaterlaus, et al., 2015). Instead, boosters draw upon porn chic aesthetics to appeal to a male gaze, despite their products being marketed toward women, reinforcing Rich's (1980) concept of 'compulsory heterosexuality'. For example, in Stephanie's post (see Figure 8 ), the squatting pose and explicit reference to her rear-end being grabbed (e.g., sand handprint) appeals to heterosexual porn tropes.

Boosters' captions reflect an ongoing conversation with their followers, who are potential customers for their products. As they are building a brand, boosters act as their own customer service representatives with a heightened requirement for emotional labour and personal interaction. Their captions are expressive-often featuring personal reflections and thoughtful commentary-yet always tied back to the product for sale. Harassment, which is heighted due to an increasing level of objectification, complicates the customer service exchange. For example, Julia's image promotes her own swimwear line for women; however, she receives sexually (and racially) confronting comments from men, such as, "Turn around before I take out my black dick and beat you like a purchased slave!" Like engagers, boosters like Julia typically do not engage with these commenters and do not remove the comments. As previously discussed, more engagement (e.g., comments) results in more potential attention for a given post. For boosters, this is critical as they seek to grow their customer base and sell their products and services. Hence, reading and making the choice to not delete such harassment simply becomes 'part of the job'.

For boosters, aesthetics, emotions, and 'porn chic' sexualisation mesh to create an entrepreneurial brand promoted through sexualised labour, with little distinguishing between the influencer as a person and the brand she is building. Connective labour mobilises sexualised labour for boosters by combining previously discussed attention-seeking digital affordances of the Instagram platform (e.g., hashtagging, tagging, commenting) and promotional practices (e.g., discount codes, exclusive giveaways) with an added element of redirecting the audience to outside e-commerce sites. The entrepreneurial products boosters create exist outside of the Instagram platform; therefore, boosters must understand how to employ connective labour to direct potential customers to purchase their products via external websites and apps, thereby monetising their sexualised labour.

\section{Performers}

Performers are influencers who offer access to themselves as commodities and perform sexualised labour to nurture the devotion of social media followers for monetary compensation. Figure 9 provides exemplary posts from performers, who engage in sexualised labour on Instagram as a method of building an audience and redirecting their followers to external outlets for distributing more overtly sexual 
Figure 9: Examples of Performers

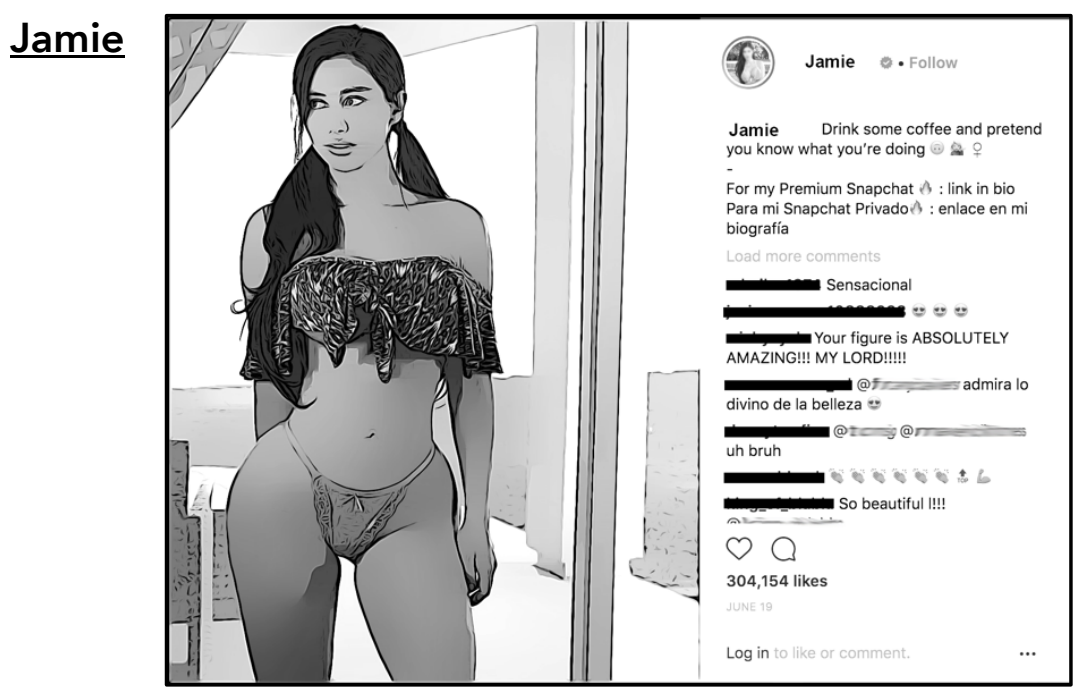

\section{Brenda}

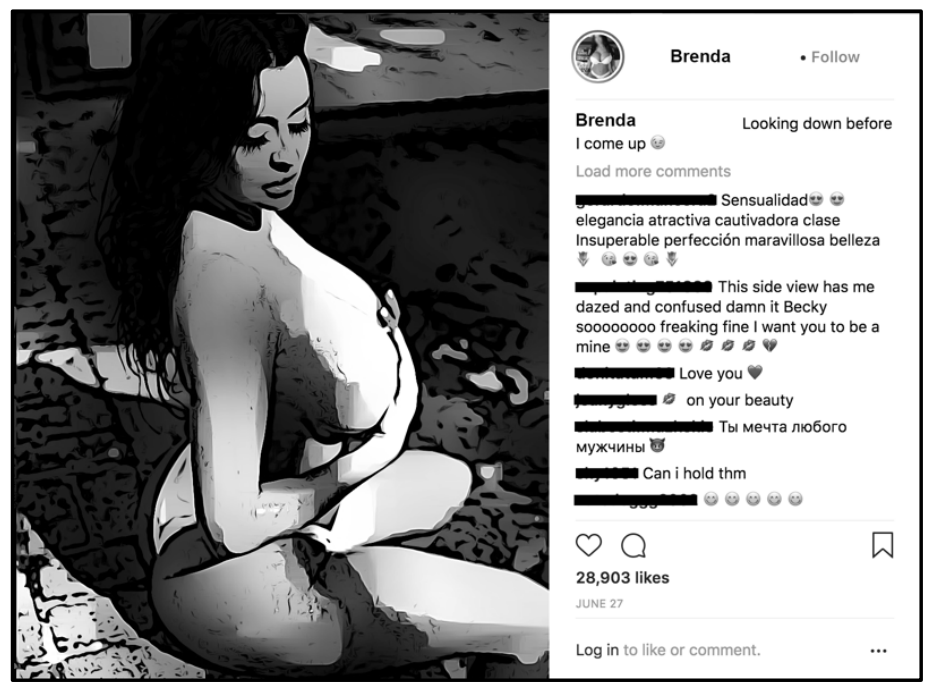

Latasia

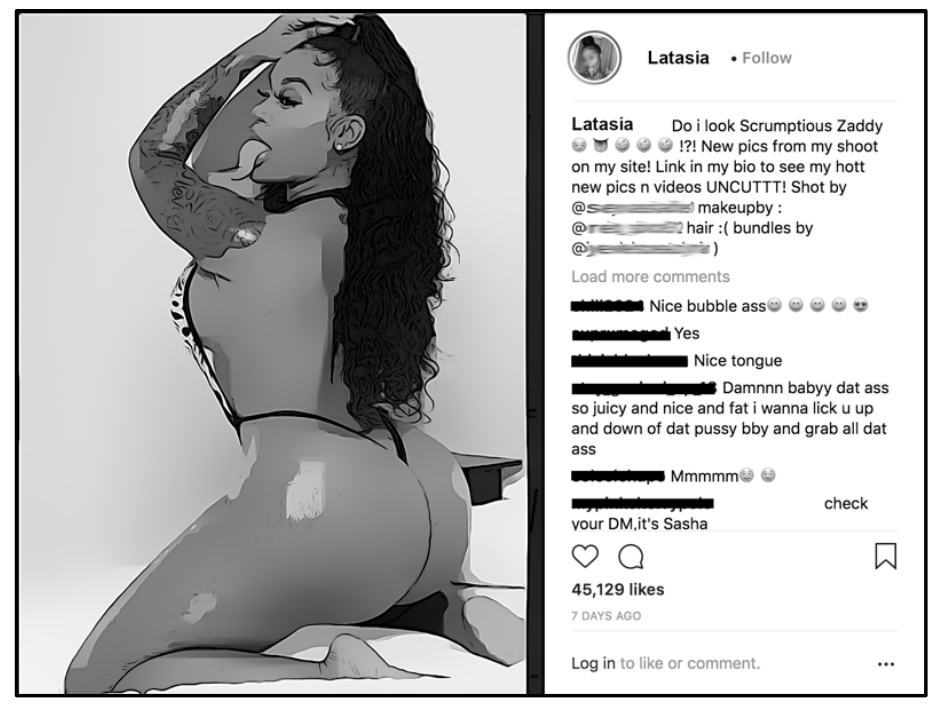


content. The performers' aesthetic is unmistakably pornographic, with posted images featuring little or no clothing, few or no props, set in private locations (e.g., bedroom), and most notably focusing on a particular body part. For example, nearly all of Latasia's images prominently feature her tongue whereas Brenda's images primarily highlight her breasts. Thus, performers' aesthetic appeal signals their bodies are available for monetary exchange while simultaneously distinguishing themselves in the marketplace based on a singular most valuable body part. This sexualised aesthetic is reinforced through performers' use of sexually symbolic emojis, which act as sexual currency to reinforce that these women are 'fuckable' (Dines, 2015). That is, in line with Tyler (2012), the sexualised performance by prosumers is not just about the body but also emphasise the importance of place. Here, other elements are sexualised in the digital arena, including sexually symbolic emojis and overtly flirtatious captions. Performers frequently use emojis, such as a smirking face (-): symbolic of flirtation), a peach (- symbolic of a butt), an eggplant ( symbolic of a penis), and three water droplets ( 0.8 : symbolic of orgasm). These emojis move beyond feeling rules of playfulness and instead signal unmistakable sexual innuendo and engagement.

Like other influencers in our data, performers receive vast numbers of sexually aggressive comments from followers; however, rather than replying on Instagram, performers perform more direct means of emotional labour elsewhere by redirecting their followers to external websites for personalised chatting and interacting. For example, Jamie redirects followers to her Snapchat, Brenda redirects followers to her OnlyFans.com page, and Latasia redirects followers to her personal website. In all cases, access to these sites involves a paid premium. For example, Jamie's Snapchat access includes three tiers, with the top billed option at $\$ 500 /$ month and described as follows, "Want the ultimate and most personal experience? With the My King Experience you will get all the perks of the other packages. To make it even more personal, I'll send you a special monthly photo collection, follow you on Instagram, and give you my personal phone number (WhatsApp)." Thus, in commodification of the self, performers use Instagram as a teaser to entice followers toward heightened forms of emotional and sexual engagement on other digital platforms-featuring constant availability and connection at a price.

Our data illustrate how performers capitalize on the meshing of aesthetic labour, emotional labour, and 'porn chic' sexualisation to build an access-based business venture rooted in sexualised labour. Connective labour mobilises this sexualised labour through digital affordances such as clickable hyperlinks to redirect followers to external websites, which allow for more sexualised content and heightened personal interactions. Even though these women approach sexualised labour as a means to a commercial end, the digital marketplace at large can, and does, exploit performers' sexualised labour for its own gain. Influencers lack control and ownership over their own digital content, due to the fluid nature of the digital 
space. In our data, their identities are impersonated and their images are frequently used as advertising click-bait, with the creators going uncredited and unpaid. For example, Latasia identifies impersonators on her profile and warns her followers, "my only page is this one and my backup account! Anything else is not me! U send money $n$ try to hit me $n$ tell me I don't wanna fuckin hear it cause I said multiple times its not me!!!!" In this way, influencers' connective labour is limited by the exploitative nature of the digital platform, whereby women's bodies can become commodities of the commons-available to anyone able to take a screenshot and profit off of performers' sexualised labour.

\section{Concluding Thoughts and Future Directions}

In this paper, we have considered the conceptual boundaries of sexualised labour, articulating it beyond the realm of the standard employment arrangements as embedded in traditional organisational settings, and considering a specific, digital context. By drawing upon the concept of prosumption, as carried out by influencers on Instagram, our study examined performances of sexualised labour bounded by 'porn chic' cultural norms. Through this, we sought to interrogate how prosumption is enacted and related to monetisation in digital culture, as well as to issues of sexualisation and pornographication, and how these subscribe to, and challenge, extant understandings of sexualised labour. In particular, we have put forward connective labour, and a more nuanced, contextually bounded, understanding of sexualisation - which recognised links to the broader cultural context of 'porn chic' and pornographication - which serve to advance research on sexualised labour, as well as pose new questions for further research in this area.

Consistent with extant literature, we observed that both aesthetic and emotional labour were clearly present in our data, although these were generally very difficult to separate. Additionally, our paper shows that aesthetic labour, emotional labour and 'porn chic' sexualisation mesh to articulate the enactment of sexualised labour by influencers on Instagram, as mobilised by connective labour. In this way, we concur with Tyler (2012) who advances a conceptualisation of sexualised labour as a complex dynamic of both performance and placement. Building upon the working definition offered earlier in the paper, we conceive sexualised labour as an embodied performance that involves a complex, interrelated dynamic of emotion, aesthetics and a modality of 'sexualisation' that cannot be separated from where it is placed. This is mobilised by what we term connective labour - the practices, skills and knowledge employed to successfully embody and negotiate this performance for attention and monetisation purposes. We next explore how our reading of the data, pushes the boundaries of extant conceptualisations of sexualised labour with regard to: the issue of freely chosen versus prescribed sexualised labour; the addition of connective labour as a key element of sexualised labour, and; questioning the meaning of 'sexualised.' 
In a departure from previous research in which an organisation prescribes the sexualised labour of workers, in our study prosumers act as entrepreneurs able to pursue multiple pathways to exploit their sexualised labour. Yet, these opportunities are marked by precarity, where - in spite of the demanding efforts required to craft sexualised labour - there is no guarantee of any financial reward and more overt sexualisation or porn chic can be one way to improve attempts at monetisation. That is, 'porn chic' on Instagram was not managerially prescribed in our data, but was rather defined by existing cultural norms. This was present across the self-commodification continuum in body poses, gestures, and stylistic choices (e.g. clothing), highlighting a fairly consistent pornified aesthetic embodied by the influencers that ranged from softer to more explicit. The monotony of this kind of representation in our study highlights the role of forces outside of a traditional management or organisational structure in shaping the performance of sexualised labour. This troubles the boundary between existing understandings of sexualised labour as either something that is managerially enforced or freely chosen by a worker. Understanding the ways in which sexualised labour might be prescribed, enforced or defined outside of traditional employment relations should prove a rich area for future research, especially given the rise of digital and precarious forms of work.

With regard to emotional labour, there are some similarities between these Instagram prosumers and other documented experiences of sexualised labourers in extant studies although, again, the boundaries were not prescribed by an employer but directed by the norms of digital culture and the platform (e.g., Instagram). The influencers documented in our study also experienced a variety of harassment; the intensity, volume, and public nature of which were amplified by the characteristics of online interactions and the ubiquity of sexually objectified imagery. Our findings highlight that, for prosumers labouring in digital culture, emotional labour is shaped by new norms and collapsing boundaries as the difference between 'work' and 'life' is blurred. Furthermore, the unbounded spatial and temporal conditions of the platform mean that these prosumers are 'always on' in a way that has not been common in traditional employment relationships within organisations. This has implications, in particular, for the study of harassment in online work environments, where there is no clear end to a shift, and the place of work is not physically bounded in the same way as much traditional employment.

Mirroring discussions in previous literature about the importance of particular knowledge resources in performing sexualised labour, our study also highlighted the importance of what we have called connective labour. This often involved understanding the overt and more covert mechanisms of the Instagram platform and the shoutout process. We offer that connective labour works to mobilise sexualised labour (in our study, primarily through the use of digital affordances such as tagging and emoji use and promotional practices such as discount codes and giveaways). The careful and strategic application of practices, skills and knowledge 
works to successfully embody and negotiate the performance of sexualised labour for attention and monetisation purposes. Naming this as connective labour helps to make visible the kind of knowledge resources gestured towards in previous studies (e.g. Tyler, 2012). Examples of connective labour could be foregrounded more in future explorations of sexualised labour as this element plays an important role in the 'successful' performance of sexualised labour and might otherwise remain hidden.

One of the most striking elements to emerge from our analysis is the connection between porn chic / pornographication and sexualised labour. Moreover, as the self-commodification continuum unfolds, more overt sexual objectification and pornographication can lead to more attention and therefore more opportunities for monetisation. This objectification, while potentially harmful in and of itself, was also more likely to be associated with more intense sexual harassment / sexually aggressive comments, suggesting that there can be significant costs tied to the monetising potential of platforms like Instagram, for female influencers. Our data therefore suggests that pornographication is a key element of the cultural background to contemporary practices of sexualised labour, especially in non-traditional labour contexts, such as digital prosumption. We also note that these cultural norms need to be recognised as a significant force which has an impact upon influencers in our data, but which exists outside the traditional employment and organisational dynamics in existing literature addressing sexualised labour. Given the cultural trend of pornographication, it not surprising to find that women often present themselves in highly sexualised / pornified ways on social media (Daniels, 2016) but how this relates to existing understandings of sexualised labour has been heretofore underexplored. We suggest that one way forward for thinking about sexualised labour is an interrogation of what is meant by 'sexualised', potentially beyond the recognized elements of sexuality, sexual desire, and/or sexual pleasure (Spiess \& Waring, 2005; Tyler, 2012; Warhurst \& Nickson, 2009). The trend of pornographication suggests a larger political economy of a particular kind of sexualised representation of women (Tyler, 2011). As pornified imagery has become the norm for 'sexy', and as 'sexy' has become increasingly demanded of women in online spaces (Daniels, 2016), it has become impossible to completely untangle notions of freely chosen sexualised labour from a pornified aesthetic in digital contexts such Instagram.

In many ways, pornographication is a useful concept to bring to understandings of sexualised labour, not least as it has the potential to more accurately delineate the kind of sexual representation that is being promoted as opposed to the broader and less bounded notion of sexualisation (Tyler \& Quek, 2016). That is, our data do not show an enormous breadth of ways in which women might wish to be sexual, but rather a fairly monotonous repetition of 'sexiness' and sexual availability that is bounded by porn chic. Given the extensive reach of pornographication (Attwood, 2011; Boyle, 2010; Dines, 2010; McNair, 2002, 2013; 
Paasonen, Nikunen \& Saarenmaa, 2008; Tyler, 2011) this is likely to be an issue relevant across a range of other settings. Furthermore, the concept of sexualised labour generally incorporates all labour that has a sexual or sexualised element, but this tells us little about the specificity of the practices; if they are, for example, heteronormative, unequal, abusive, or potentially empowering. We argue for the consideration of possible modalities of sexualised labour that interrogate the relationship between 'sexualisation' and the shaping role of cultural norms in 'managing' women's sexualised representations. In turn, this offers the possibility of greater precision about the context in which particular kinds of sexualised labour take place, and the underlying power dynamics that may underpin them. 


\section{References}

Abidin, C. (2015). Communicative Intimacies: Influencers and Perceived Interconnectedness. ada: A Journal of Gender, New Media, and Technology, 8.

Abidin, C. (2016a). "Aren't These Just Young, Rich Women Doing Vain Things Online?": Influencer Selfies as Subversive Frivolity. Social Media + Society, 2(2).

Abidin, C. (2016b). Visibility Labour: Engaging with Influencers' Fashion Brands and \#OOTD Advertorial Campaigns on Instagram. Media International Australia, 161(1), 86-100.

Adkins, L. (1995). Gendered Work: Sexuality, Family and the Labour Market. Bristol, PA: Open University Press.

Anderson-Gough, F., Grey, C., \& Robson, K. (1998). 'Work Hard, Play Hard': An Analysis of Organizational Cliche in Two Accountancy Practices. Organization, 5(4), 565-592.

Ashforth, B., \& Humphrey, R. (1993). Emotional Labor in Service Roles: The Influence of Identity. The Academy of Management Review, 18(1), 88-115.

Attwood, F. (2011). The Paradigm Shift: Pornography Research, Sexualization and Extreme Images. Sociology Compass, 5(1), 13-22.

Bolton, S. C. (2005). Emotion Management in the Workplace. New York, NY: Palgrave Macmillan.

Bolton, S. C., \& Boyd, C. (2003). Trolley Dolly or Skilled Emotion Manager? Moving on from Hochschild's Managed Heart. Work, Employment \& Society, 17(2), 289-308.

Bonsu, S. K., \& Darmody, A. (2008). Co-creating Second Life: Market-Consumer Cooperation in Contemporary Economy. Journal of Macromarketing, 28(4), 355-368.

Boyle, K. (2010). EverydayPpornography. London: Routledge.

Boyle, K. (2018). The Implications of Pornification: Pornography, the Mainstream and False Equivalences. In N. Lombard (Ed.), The Routledge Handbook of Gender and Violence (pp. 85-96). London: Routledge.

Braun, V., \& Clarke, V. (2006). Using Thematic Analysis in Psychology. Qualitative Research in Psychology, 3(2), 77-101.

Bucher, T., \& Helmond, A. (2018). The Affordances of Social Media Platforms. In J. Burgess, T. Poell, \& A. Marwick (Eds.), The SAGE Handbook of Social Media (pp. 233-253). London, UK: SAGE Publications.

Büscher, B., \& Igoe, J. (2013). 'Prosuming' Conservation? Web 2.0, Nature and the Intensification of Value-producing Labour in Late Capitalism. Journal of Consumer Culture, 13, 283-305. 
Carrotte, E. R., Prichard, I., \& Lim, M. S. C. (2017). 'Fitspiration' on Social Media: A Content Analysis of Gendered Images. Journal of medical Internet research, 19(3), e95.

Kids Media Centre. (2018). Evolution of the Shoutout. Retrieved from http://www.hashtaginstafame.com/the-evolution-of-the-shoutout/?rq=shoutout.

Cheng, A. (2017). What Is a 'Plandid'? Here's Why Celebrities Are All About This Instagram Trend. billboard. Retrieved from https://www.billboard.com/articles/news/lifestyle/7948968/instagram-posingmade-easy-plandid.

Comor, E. (2011). Contextualizing and Critiquing the Fantastic Prosumer: Power, Alienation and Hegemony. Critical Sociology, 37, 309-327.

Cova, B., \& Dalli, D. (2009). Working Consumers: The Next Step in Marketing Theory? Marketing Theory, 9, 315-339.

Daniels, E. A. (2016). Sexiness on Social Media: The Social Costs of Using a Sexy Profile Photo. Sexualization, Media, \& Society, 2(4), 1-10.

Davenport, T. H., \& Beck, J. C. (2001). The Attention Economy: Understanding the New Currency of Business. Boston, MA: Harvard Business School Press.

Davis, P. (2001). Sexualization and Sexuality in Sport. In W. Morgan, K. Meier, \& A. Schneider (Eds.), Ethics in Sport (pp. 285-292). Champaign, IL: Human Kinetics.

Dean, D. (2005). Recruiting a Self: Women Performers and Aesthetic Labour. Work, Employment \& Society, 19(4), 761-774.

Dines, G. (2010). Pornland: How Pornography Has Hijacked Our Sexuality. New York, NY: Beacon.

Dines, G. (Producer). (2015, 24/01/2018). Growing Up in a Pornified Culture. TEDx. Retrieved from https://www.youtube.com/watch?v=_YpHNImNsx8

Duffy, B. (2017). (Not) Getting Paid to Do What You Love: Gender, Social Media, and Aspirational Work. New Haven, CT: Yale University Press.

Dujarier, M.-A. (2016). The Three Sociological Types of Consumer Work. Journal of Consumer Culture, 16, 555-571. doi:10.1177/1469540514528198

Elliott, C., \& Stead, V. (2018). Constructing Women's Leadership Representation in the UK Press During a Time of Financial Crisis: Gender capitals and dialectical tensions. Organization Studies, 39(1), 19-45.

Entwistle, J., \& Wissinger, E. (2006). Keeping Up Appearances: Aesthetic Labour in the Fashion Modelling Industries of London and New York. The Sociological Review, 54(4), 774-794.

Fereday, J., \& Muir-Cochrane, E. (2006). Demonstrating Rigor Using Thematic Analysis: A Hybrid Approach of Inductive and Deductive Coding and Theme Development. International Journal of Qualitative Methods, 5(1), 80-92.

Filby, M. P. (1992). 'The Figures, the Personality and the Bums': Service Work and Sexuality. Work Employment \& Society, 6(1), 23-42. 
Fontenelle, I. A. (2015). Organisations as Producers of Consumers. Organization, 22, 644-660.

Fredrickson, B. L., \& Roberts, T.-A. (1997). Objectification Theory: Toward Understanding Women's Lived Experiences and Mental Health Risks. Psychology of Women Quarterly, 21(2), 173-206.

Fuchs, C. (2013). New Media, Web 2.0 and Surveillance. Sociology Compass, 5(2), 134-147.

Gabriel, Y., Korczynski, M., \& Rieder, K. (2015). Organizations and their Consumers: Bridging Work and Consumption. Organization, 22(5), 629-643.

Goldhaber, M. H. (1997). The Attention Economy and the Net. First Monday, 2(4). Grandey, A. A. (2000). Emotion Regulation in the Workplace: A New Way to Conceptualize Emotional Labor. Journal of Occupational Health Psychology, 5(1), 95-110.

Hall, P., West, J., \& Mclntyre, E. (2012). Female Self-Sexualization in MySpace.com Personal Profile Photographs. An Interdisciplinary Quarterly, 16(1), 1-16.

Harvey, H. B., \& Robinson, K. (2007). Hot Bodies on Campus: The Performance of Porn Chic. In A. C. Hall \& M. J. Bishop (Eds.), Pop-Porn: Pornography in American Culture (pp. 57-74). Westport, CT: Praeger.

Hochschild, A. R. (1983). The Managed Heart: Commercialization of Human Feeling. Berkeley, CA: University of California Press.

Instagram. (2018). Verified Badges. Retrieved from https://help.instagram.com/1080769608648426.

Jang, J. Y., Han, K., \& Lee, D. (2015). No Reciprocity in Liking Photos: Analyzing Like Activities in Instagram. Paper presented at the Proceedings of the 26th ACM Conference on Hypertext \& Social Media.

Jin, D. Y., \& Feenberg, A. (2015). Commodity and Community in Social Networking: Marx and the Monetization of User-Generated Content. The Information Society, 31(1), 52-60.

Kapidzic, S., \& Herring, S. C. (2015). Race, Gender, and Self-presentation in Teen Profile Photographs. New Media \& Society, 17(6), 958-976.

Korczynski, M. (2003). Communities of Coping: Collective Emotional Labour in Service Work. Organization, 10(1), 55-79.

Kralj Novak, P., Smailović, J., Sluban, B., \& Mozetič, I. (2015). Sentiment of Emojis. PLOS ONE, 10(12), e0144296.

Kress, G. R., \& Van Leeuwen, T. (2006). Reading Images: The Grammar of Visual Design (Vol. 2nd Edition). London, UK: Routledge.

Liu, H., Cutcher, L., \& Grant, D. (2015). Doing Authenticity: The Gendered Construction of Authentic Leadership. Gender, Work \& Organization, 22(3), 237-255.

Lynch, A. (2012). Porn Chic: Exploring the Contours of Raunch Eroticism. London, UK: Berg Publishers. 
Manago, A. M., Graham, M. B., Greenfield, P. M., \& Salimkhan, G. (2008). SelfPresentation and Gender on MySpace. Journal of Applied Developmental Psychology, 29(6), 446-458.

McNair, B. (2013). Porno? Chic!: How Pornography Changed the World and Made it a Better Place. London: Routledge.

Mears, A. (2014). Aesthetic Labor for the Sociologies of Work, Gender, and Beauty. Sociology Compass, 8, 1330-1343.

Mears, A., \& Connell, C. (2016). The Paradoxical Value of Deviant Cases: Toward a Gendered Theory of Display Work. Signs: Journal of Women in Culture \& Society, 41, 333-359.

mediakix. (2018). Why the Influencer Marketing Industry Will Be a \$5-\$10 Billion Dollar Market In The Next 5 Years. Retrieved from http://mediakix.com/2018/03/influencer-marketing-industry-ad-spendchart/\#gs.eTfr73kl.

Meyerowitz, J. (1996). Women, cheesecake, and borderline material: Responses to girlie pictures in the mid-twentieth-century US. Journal of Women's History, 8(3), 9-35.

Morris, J., \& Feldman, D. (1996). The dimensions, antecedents, and consequences of emotional labor. Academy of Management Review, 21(4), 986-1011.

Otis, E. (2011). Markets and Bodies: Women, Service Work, and the Making of Inequality in China. Stanford, CA: Stanford University Press.

Paasonen, S., Nikunen, K., \& Saarenmaa, L. (2007). Pornification: Sex and Sexuality in Media Culture. Oxford, UK: Berg Publishers.

Paul, P. (2005). Pornified: How Pornography is Transforming Our Lives, Our Relationships, and Our Families. New York, NY: Macmillan.

Pringle, R. (1989). Bureaucracy, Rationality and Sexuality: The Case of Secretaries. In J. Hearn, D. Sheppard, P. Tancred-Sheriff, \& G. Burrell (Eds.), The Sexuality of Organisation. London, UK: SAGE.

Rich, A. (1980). Compulsory Heterosexuality and Lesbian Existence. Signs: Journal of Women in Culture and Society, 5(4), 631-660.

Ringrose, J. (2011). Are You Sexy, Flirty, or a Slut? Exploring 'Sexualization' and How Teen Girls Perform/Negotiate Digital Sexual Identity on Social Networking Sites. In R. Gill \& C. Scharff (Eds.), New Femininities: Postfeminism, Neoliberalism, and Subjectivity (pp. 99-116). New York, NY: Palgrave Macmillan.

Ritzer, G., \& Jurgenson, N. (2010). Production, Consumption, Prosumption: The Nature of Capitalism in the Age of the Digital 'Prosumer'. Journal of Consumer Culture, 10, 13-36.

Robert V. Kozinets, Kristine de Valck, Andrea C. Wojnicki, \& Wilner, S. J. S. (2010). Networked Narratives: Understanding Word-of-Mouth Marketing in Online Communities. Journal of Marketing, 74(2), 71-89 
Schroeder, J. E. (2011). Style and Strategy: Snapshot Aesthetics in Brand Culture. In P. Quattrone, N. Thrift, C. Mclean, \& F.-R. Puyou (Eds.), Imagining Organizations: Performative Imagery in Business and Beyond (pp. 129-151). New York, NY: Routledge.

Schweingruber, D., \& Berns, N. (2005). Shaping the Selves of Young Salespeople through Emotion Management. Journal of Contemporary Ethnography, 34(6), 679-706.

Scollon, R., \& Scollon, S. W. (2003). Discourses in Place: Language in the Material World. London, UK: Routledge.

Spiess, L., \& Waring, P. (2005). Aesthetic Labour, Cost Minimisation and the Labour Process in the Asia Pacific Airline Industry. Employee Relations, 27, 193-207.

Statista. (2018). Most popular social networks worldwide as of January 2018, ranked by number of active users (in millions). Retrieved from https://www.statista.com/statistics/272014/global-social-networks-ranked-bynumber-of-users/.

Terranova, T. (2012). Attention, Economy and the Brain. Culture Machine, 13.

Thompson, C. J. (1997). Interpreting Consumers: A Hermeneutical Framework for Deriving Marketing Insights from the Texts of Consumers' Consumption Stories. Journal of Marketing Research, 34(4), 438-455.

Turley, L. W., \& Moore, P. A. (1995). Brand Name Strategies in the Service Sector. Journal of Consumer Marketing, 12(4), 42-50.

Tyler, M. (2011). Tainted Love: From Dirty Work to Abject Labour in Soho's Sex Shops. Human Relations, 64, 1477-1500.

Tyler, M. (2011). Selling Sex Short: The Pornographic and Sexological Construction of Women's Sexuality in the West. Newcastle: Cambridge Scholars.

Tyler, M. (2012). Working in the other Square Mile: Performing and Placing Sexualized Labour in Soho's Sex Shops. Work, Employment and Society, 26, 899-917.

Tyler, M., \& Quek, K. (2016). Conceptualizing Pornographication. Sexualization, Media, \& Society, 2(2).

Tyler, M., \& Taylor, S. (1998). The Exchange of Aesthetics: Women's Work and 'The Gift'. Gender, Work \& Organization, 5(3), 165-171.

Vaterlaus, J. M., Patten, E. V., Roche, C., \& Young, J. A. (2015). \#Gettinghealthy: The Perceived Influence of Social Media on Young Adult Health Behaviors. Computers in Human Behavior, 45, 151-157.

Walther, J. B. (1996). Computer-Mediated Communication: Impersonal, Interpersonal, and Hyperpersonal Interaction. Communication Research, 23(1), 3-43.

Warhurst, C., \& Nickson, D. (2007). Employee Experience of Aesthetic Labour in Retail and Hospitality. Work, Employment \& Society, 21(1), 103-120. 
Warhurst, C., \& Nickson, D. (2009). 'Who's Got the Look?' Emotional, Aesthetic and Sexualized Labour in Interactive Services. Gender, Work \& Organization, 16, 385-404.

Witz, A., Warhurst, C., \& Nickson, D. (2003). The Labour of Aesthetics and the Aesthetics of Organization. Organization, 10(1), 33-54.

Zurbriggen, E., Collins, R., Lamb, S., Roberts, T., Tolman, D., Ward, M., \& Blake, J. (2007). Report of the APA task force on the sexualization of girls. Retrieved from https://www.apa.org/pi/women/programs/girls/report. American Psychological Association: Washington, DC.

Zwick, D., Bonsu, S. K., \& Darmody, A. (2008). Putting Consumers to Work: Cocreation and New Marketing Govern-mentality. Journal of Consumer Culture, 8, 163-196. 